\title{
Reciprocal Control of the Circadian Clock and Cellular Redox State - a Critical Appraisal
}

\author{
Marrit Putker* and John Stuart O’Neill*
}

\begin{abstract}
Redox signalling comprises the biology of molecular signal transduction mediated by reactive oxygen (or nitrogen) species. By specific and reversible oxidation of redoxsensitive cysteines, many biological processes sense and respond to signals from the intracellular redox environment. Redox signals are therefore important regulators of cellular homeostasis. Recently, it has become apparent that the cellular redox state oscillates in vivo and in vitro, with a period of about one day (circadian). Circadian timekeeping allows cells and organisms to adapt their biology to resonate with the 24-hour cycle of day/night. The importance of this innate biological timekeeping is illustrated by the association of clock disruption with the early onset of several diseases (e.g. type II diabetes, stroke and several forms of cancer). Circadian regulation of cellular redox balance suggests potentially two distinct roles for redox signalling in relation to the cellular clock: one where it is regulated by the clock, and one where it regulates the clock. Here, we introduce the concepts of redox signalling and cellular timekeeping, and then critically appraise the evidence for the reciprocal regulation between cellular redox state and the circadian clock. We conclude there is a substantial body of evidence supporting circadian regulation of cellular redox state, but that it would be premature to conclude that the converse is also true. We therefore propose some approaches that might yield more insight into redox control of cellular timekeeping.
\end{abstract}

\section{INTRODUCTION}

Intracellular redox state determines the direction of redox reactions that occur in the cell, and is determined by the balance of pro-oxidants compared with antioxidants. Oxidising conditions result from an increase in levels of pro-oxidant reactive oxygen (or nitrogen) species (ROS, or RNS) or a decrease in reducing power. Although high levels of ROS (a state known as oxidative

Laboratory of Molecular Biology, Medical Research Council, Francis Crick Avenue, Cambridge CB2 0QH, UK

*Correspondence: oneillj@mrc-Imb.cam.ac.uk (JSO); mputker@mrcImb.cam.ac.uk (MP)

Received 23 November, 2015; accepted 26 November, 2015; published online 25 January, 2016

Keywords: biological clock, circadian timekeeping, cysteine oxidation, redox signalling stress) are detrimental to the cellular environment, low levels of ROS are required for normal signalling in healthy cells (Schieber and Chandel, 2014).

One of the first examples of functional signalling initiated by ROS (aka redox signalling) was recognised in the mid-1970s, when it was observed that high levels of oxidising reagents induce an insulin-like response (Czech et al., 1974). Indications that ROS can also induce a direct transcriptional response came from studies on bacterial OxyR (Storz et al., 1990) and mammalian AP-1 (c-Fos and c-Jun) (Abate et al., 1990) transcription factors, which showed that oxidation of these proteins modulates their transcriptional activities. By the mid-1990s, Sundaresan and colleagues had noted that activation of the platelet derived growth factor (PDGF) signalling pathway induces an increase in intracellular hydrogen peroxide $\left(\mathrm{H}_{2} \mathrm{O}_{2}\right)$ concentration that is required for functional PDGF signalling. Based on these findings, they proposed that $\mathrm{H}_{2} \mathrm{O}_{2}$ potentially functioned as a second messenger in this pathway (Sundaresan et al., 1995), a hypothesis that was subsequently confirmed and then expanded to include other signalling pathways (as exemplified below).

In contrast to other second messengers (like calcium or cAMP), $\mathrm{H}_{2} \mathrm{O}_{2}$ is not recognised by specialised binding (or effector) proteins. Instead, signalling through $\mathrm{H}_{2} \mathrm{O}_{2}$ proceeds via the oxidation of reactive cysteine residues. The response to a $\mathrm{H}_{2} \mathrm{O}_{2}$ transient is not binary however, and can lead to different molecular effects, depending on the concentration of $\mathrm{H}_{2} \mathrm{O}_{2}$, the identity of the oxidised cysteine, the degree of oxidation, and the nature of the oxidised cysteine's subsequent reactions. Essential to this $\mathrm{H}_{2} \mathrm{O}_{2}$-mediated signal transduction therefore, is the principle of differential sensitivity of intracellular cysteines to oxidation. This is readily understood in the case of buried vs. surface-exposed cysteine residues but, as discussed below, also includes differential redox sensitivity of surface cysteines within the same protein.

\section{FORMATION AND DECOMPOSITION OF REACTIVE OXYGEN SPECIES}

Reactive oxygen species (ROS) is a generic term for many different oxygen-derivatives, including the extremely reactive hydroxyl radical $(\mathrm{OH})$, highly reactive superoxide anion $\left(\mathrm{O}_{2}{ }^{--}\right)$ and the less reactive but more abundant and diffusible $\mathrm{H}_{2} \mathrm{O}_{2}$; these latter features eminently suit $\mathrm{H}_{2} \mathrm{O}_{2}$ for its signalling role. As a result of aerobic metabolism, superoxide anions are constantly formed as natural by-products of mitochondrial respiration; indeed it has been estimated that about $1-2 \%$ of 
all acceptor oxygen escapes full reduction to water and exits the mitochondria as $\mathrm{O}_{2}{ }^{--}$(Aon et al., 2003). Moreover, $\mathrm{O}_{2}{ }^{-}$is actively produced by NADPH oxidases (NOXs) and xanthine oxidases (XO) (Dickinson, 2015) in response to growth factor signalling e.g. insulin and PDGF pathways.

Due to its high reactivity, an increase in $\mathrm{O}_{2}{ }^{-}$levels induces damage to essential cellular components such as DNA, fatty acids and proteins. To protect themselves against ROSinduced damage, cells express antioxidant systems that decompose ROS. Mitochondrial manganese superoxide dismutase (MnSOD) and cytoplasmic copper/zinc superoxide dismutase (CuZnSOD) catalyse the dismutation of $\mathrm{O}_{2}{ }^{--}$to less reactive $\mathrm{H}_{2} \mathrm{O}_{2}$ (McCord and Fridovich, 1969). Proteins that control cytoplasmic $\mathrm{H}_{2} \mathrm{O}_{2}$ levels are peroxiredoxin 1 and 2 (PRX1 and 2) and glutathione peroxidase (GPX) (Hanschmann et al., 2013). Followed protein oxidation, PRX and GPX are recycled via reduction by the thioredoxin (TXN) and glutaredoxin (GRX) systems, respectively. Both TXN and GRX are ultimately supplied with reducing equivalents in the form of $\mathrm{NADPH}$ - the cytosol's master redox currency (see below).

\section{CYSTEINE-DEPENDENT REDOX SIGNALLING}

As noted above, redox signalling proceeds through the oxidation of specific cysteine residues in a wide variety of proteins. The sulphur atom in cysteine is sensitive to several degrees of oxidation by $\mathrm{H}_{2} \mathrm{O}_{2}$ (Fig. $1 \mathrm{~A}$ ). In its reduced state, it exists as a thiol $(-\mathrm{SH})$ or as a deprotonated thiolate anion $\left(-\mathrm{S}^{-}\right)$. The thiolate anion is most susceptible to oxidation, and upon successive encounters with $\mathrm{H}_{2} \mathrm{O}_{2}$, it reacts to form first a sulphenic acid $(-\mathrm{SOH})$, then a sulphinic acid $\left(-\mathrm{SO}_{2} \mathrm{H}\right)$, then a fully oxidised sulphonic acid $\left(-\mathrm{SO}_{3} \mathrm{H}\right)$. Of these, a sulphinic acid can be actively reduced by sulphiredoxin1 (SRX) to form a sulphenic acid (Chang et al., 2004; Woo et al., 2003). Both sulphinic and sulphonic forms of cysteine may be referred to as "over-" or "hyperoxidised", but only the sulphonic form is irreversibly oxidised,

The initial protonation state of a cysteine residue is determined by its pKa. The pKa of free cysteine is 8.3-8.5, meaning that at cytosolic $\mathrm{pH}(\sim 7.4)$ free cysteines are fully protonated. Similarly, GSH has a pKa of 8.8 (Winterbourn and Metodiewa, 1999 ) and is fully protonated under physiological circumstances. Instead, redox sensitive proteins have a much lower pKa: the catalytic cysteine of TXN has a pKa of 6.5 (Goldman et al., 1995), the pKa of the catalytic cysteine in PTP1B is even lower at 5.4 (Monteiro and Stern, 1996), and PRX catalytic cysteines have a pKa between 5-6 (Peskin et al., 2007). Low pKa, however, is not sufficient to explain the higher reactivity of some cysteines compared with others. For example, although both PRX2 and PTP1B catalytic cysteines are fully deprotonated at physiological $\mathrm{pH}$, the reaction rate of $\mathrm{PRX} 2$ with $\mathrm{H}_{2} \mathrm{O}_{2}$ is approximately six orders of magnitude higher than PTP1B. It is thought therefore, that residues surrounding highly redoxsensitive cysteines are critical for determining their activity, not only by facilitating an electrostatic microenvironment which favours deprotonation but also stabilising the transition state required for their high reactivity (Bindoli and Rigobello, 2012). For example, PRX2 and 3 contain a highly conserved arginine residue that is critical to their peroxidase function (Nagy et al., 2011).

Sulphenic acids are believed to be short-lived oxidation intermediates as they favour reaction with other cysteine-thiols to form intra- or intermolecular disulphides (-S-S-) (Fig. 1A)
(Rehder and Borges, 2010). Intramolecular disulphides potentially mediate conformational changes that facilitate cellular signal transduction. For example, formation of an intramolecular disulphide in Kelch-like ECH-associated protein 1 (KEAP1) inhibits its binding to the transcription factor NRF2 (Nuclear factor (erythroid-derived)-like 2). As KEAP1 facilitates NRF2 ubiquitination and degradation, oxidising conditions lead to activation of NRF2 and its transcriptional program. Being an important regulator of the cellular antioxidant response (with targets such as SOD, PRX and SRX) this allows for a proper cellular response to oxidative insults (Hayes and DinkovaKostova, 2014).

Intermolecular disulphides lead to covalently linked (homo- or hetero) dimers or multimers. Such a covalent interaction potentially stabilises otherwise transient interactions, thereby allowing changes in protein-protein interaction-mediated signalling (Cremers and Jakob, 2013; Putker et al., 2014a). Several observations indicate that such intermolecular disulphides can directly regulate cytosolic enzyme activity. For example, the activities of protein kinase A (PKA) (Burgoyne et al., 2015), protein kinase G (PKG) (Burgoyne et al., 2007; Prysyazhna et al., 2012) and apoptosis signal-regulating kinase 1 (ASK1) (Nadeau et al., 2007) are under disulphide-mediated redox control. Several transcription factors have also been shown to be regulated by disulphide-mediated interactions, with wellknown examples being the Forkhead Box $\mathrm{O}$ tumour suppressor proteins, FOXO3 and FOXO4, both of which having been implicated in a plethora of disulphide-dependent complexes (Dansen et al., 2009; Putker et al., 2013; 2014b). ROS-induced nuclear accumulation and activation of both proteins is regulated in a (distinct) disulphide-dependent manner.

Alternatively, sulphenic acids can form intermolecular disulphides with the highly abundant tripeptide glutathione (Glu-CysGly) (GSH), known as glutathionylation. Glutathionylation is considered an important posttranslational modification that serves several functions. First of all, it protects the sulphur from hyperoxidation, thereby increasing protein stability. Moreover, glutathionylation affects protein activity by altering cysteine function (see below) or may form new docking sites for proteinprotein interactions (Grek et al., 2013).

Due to the nucleophilic character of the thiolate anion, cysteines often play important roles in protein activity or structure. Therefore, besides mediating disulphide-dependent signalling, oxidation of functional cysteines can greatly affect cellular signalling. Many enzymes feature catalytic cysteines in their active sites, with oxidation leading to enzymatic inhibition. Under physiological conditions, sulphenic acid formation has been shown to inhibit the activities of enzymes as diverse as phospho-tyrosine phosphatases [e.g. protein tyrosine phosphatase 1B (PTP1B) (Lee et al., 1998)], deubiquitinating enzymes [e.g. ubiquitin specific peptidase 1 (USP1), USP7 and A20 (Cotto-Rios et al., 2012; Kulathu et al., 2013)] and the glycolytic enzyme GAPDH (Peralta et al., 2015). In addition to catalytic cysteine oxidation, cysteines are often found at sites of structural significance, and oxidation has therefore been suggested to induce functional changes in protein structure. For example, cysteines in zinc finger motifs are crucial to secondary structure and DNA binding. Oxidation of zinc finger cysteines leads to $\mathrm{Zn}^{2+}$ release and subsequent conformational change/loss of DNA binding, and increased free $\mathrm{Zn}^{2+}$ itself can elicit further signalling responses. This redox control by $\mathrm{Zn}^{2+}$ exclusion has been demonstrated for the zinc finger transcription factors p53 (Rainwater et al., 1995) and SP-1 (Webster et al., 2001; Wu et al., 1996), for example. 
A

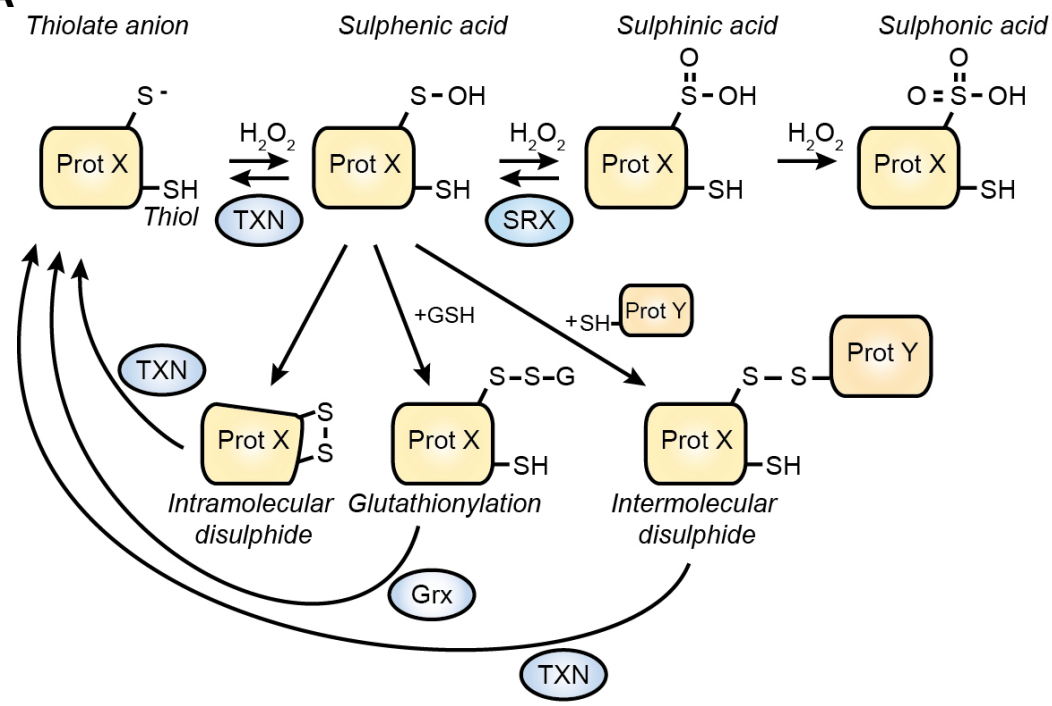

Fig. 1. Oxidative cysteine modifications and their recycling. (A) Overview of oxidative cysteine modifications and their respective reduction procces. Abbreviations: Prot $\mathrm{X}$ : protein $X-T X N$ : thioredoxin - SRX: sulfiredoxin - GRX: glutaredoxin. (B) Reduction of an inter- or intramolecular disulphide by the thioredoxin system. Thioredoxin reductase (TXNR) is a selenoprotein, containing a selenocysteine (Se) instead of a normal cysteine.
B

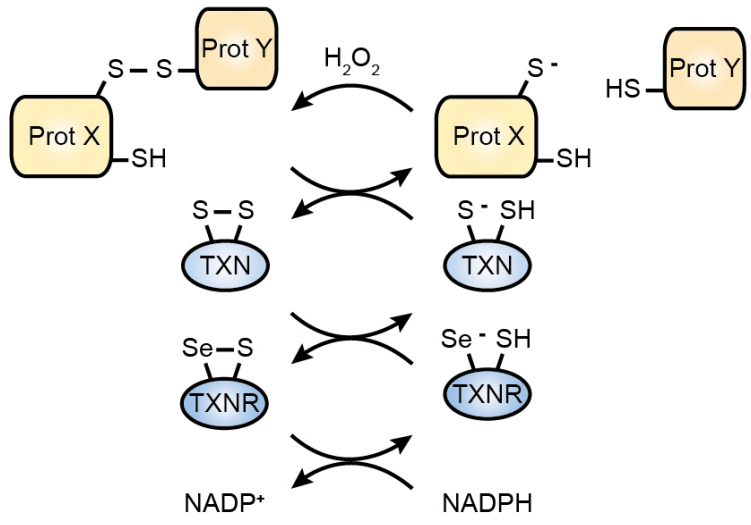

Excepting $-\mathrm{SO}_{3}$, all cysteine derivatives described above are reversible. Inter- or intramolecular disulphides become reduced through the TXN and GRX systems (Hanschmann et al., 2013). Recycling of TXN is catalysed by thioredoxin reductase (TXNR) (Fig. 1B), whereas GRX recycles by oxidation transfer to a free GSH molecule. Oxidised GSH (GSSG) in turn is recycled by glutathione reductase (GR), with both oxidised TXNR and GR being ultimately reduced at the expense of NADPH. The intracellular GSH pool and NADP/NADPH ratio are thus critical determinants of cellular reduction potential.

\section{SPECIFICITY OF CYSTEINE-DEPENDENT REDOX SIGNALLING}

Cells possess extensive antioxidant systems to maintain intracellular ROS within a physiological range. GPX, PRX1 and 2 are highly abundant proteins, and their reaction rates with $\mathrm{H}_{2} \mathrm{O}_{2}$ are 4-6 orders of magnitude above that of most redox sensitive cysteines. For example, the rate constant of PRX2 for its reaction with $\mathrm{H}_{2} \mathrm{O}_{2}$ is $\sim 4^{*} 10^{7} \mathrm{M}^{-1} \mathrm{~s}^{-1}$, whereas that of PTP1B is $20 \mathrm{M}^{-}$ ${ }^{1} \mathrm{~s}^{-1}$. As the protein levels of PRX1 and 2 are high [20 $\mu \mathrm{M}$ versus e.g. 0.1 $\mu \mathrm{M}$ for PTP1B (Winterbourn and Hampton, 2008)], and their reaction rate with $\mathrm{H}_{2} \mathrm{O}_{2}$ is much higher than most protein thiols, it seems unlikely that PTP1B (or another similarly reac- tive protein thiol) would become oxidised upon physiological increases in $\mathrm{H}_{2} \mathrm{O}_{2}$ (i.e. those that mediate signalling, without inducing damage) (Fig. 2A). Oxidation and inhibition of PTP1B does occur however (Lee et al., 1998), as do the other protein oxidations described above. Although the sequence of molecular events during each oxidation are incompletely understood, in general the mechanism allowing cells to detect and respond to $\mathrm{H}_{2} \mathrm{O}_{2}$-induced cysteine oxidation is understood by (a combination of) two models.

In the first model, localised inactivation of PRX1/2 allows other proteins to become oxidised (Fig. 2B). The activity of $\mathrm{PRX}$ proteins is regulated by either oxidative or non-oxidative modifications. In the first case, localised increase in $\mathrm{H}_{2} \mathrm{O}_{2}$ levels (e.g. through NOX activation) overwhelms the "floodgate" of the local antioxidant capacity leading to hyperoxidation of PRX peroxidatic cysteines, preventing their recycling. A localised pool of inactivated $\mathrm{H}_{2} \mathrm{O}_{2}$-scavenging enzymes results, allowing oxidation of less reactive thiol proteins (Wood et al., 2003). Upon cessation of $\mathrm{H}_{2} \mathrm{O}_{2}$ production, the sulphinic acids are (slowly) recycled via SRX (Chang et al., 2004), restoring normal redox balance. Besides oxidation-mediated regulation, tyrosine kinase-mediated phosphorylation of PRX1-tyr194 (e.g. by SRC) inactivates PRX1, contributing to localised inactivation of $\mathrm{H}_{2} \mathrm{O}_{2}$ scavenging enzymes. Interes- 
A

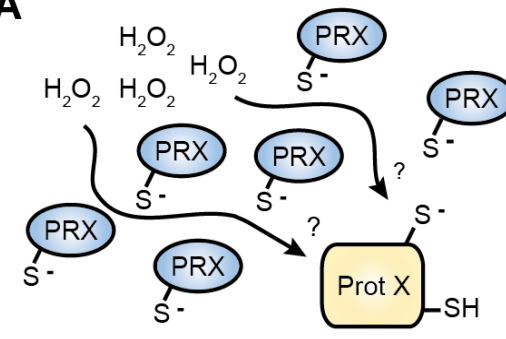

C

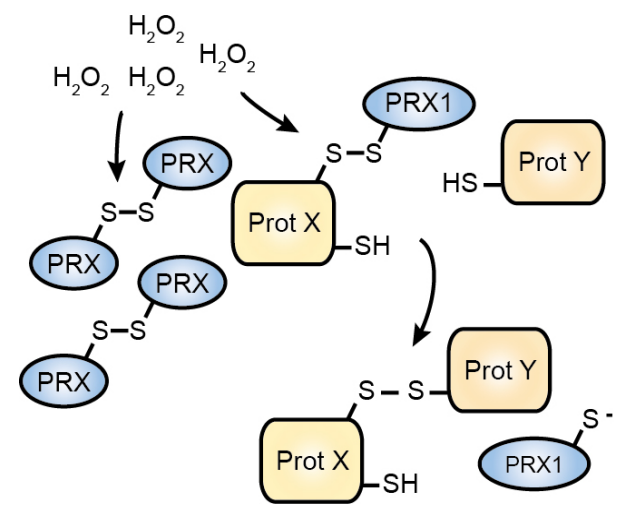

B

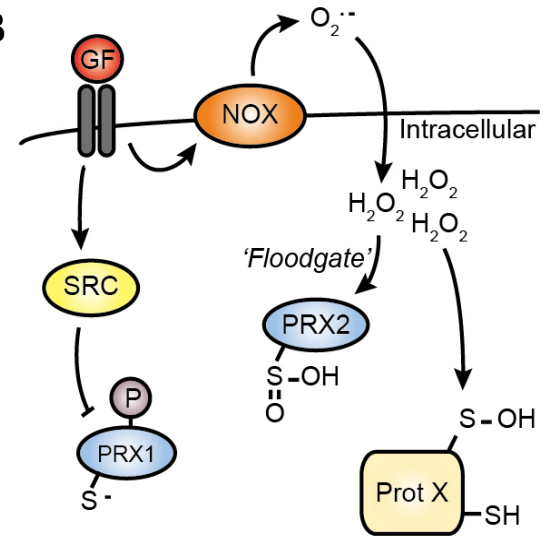

Fig. 2. Models for how cysteine oxidation occurs in vivo. (A) High abundance and reactivity of $\mathrm{PRX}$ proteins makes it unlikely that any other cysteine in the cytoplasm could become oxidised. (B) Growth factor signalling induces a localised increase in $\mathrm{H}_{2} \mathrm{O}_{2}$ by inhibiting PRX proteins in at least two manners. The resulting increase in $\mathrm{H}_{2} \mathrm{O}_{2}$ allows the oxidation of less reactive thiols. (C) PRX-mediated redox relay. Oxidised PRX transfers its oxidation to other proteins. Interaction with PRX can mediate the oxidation of specific cysteines upon an increase of the $\mathrm{H}_{2} \mathrm{O}_{2}$ concentration.

tingly, PRX2 is insensitive to such phosphorylation-dependent regulation. Instead, PRX2 is much more sensitive than PRX1 to hyperoxidation (Woo et al., 2010). Taken together, oxidation-dependent and -independent mechanisms lead to inactivation of $\mathrm{PRX}$ proteins, allowing $\mathrm{H}_{2} \mathrm{O}_{2}$ to oxidise other proteins and activate redox signalling.

The second model also uses PRX oxidation as a starting point. In this case, cysteines are not oxidised directly by $\mathrm{H}_{2} \mathrm{O}_{2}$, but through PRX-mediated oxidation relay processes (Fig. 2C). Instead of forming a homodimer with another PRX protein, oxidised PRX can transfer its oxidation state to specific target proteins, thereby inducing disulphide formation on its binding partner resulting in PRX reduction (Jarvis et al., 2012; Sobotta et al., 2014). This is functionally equivalent to the oxidative protein folding catalysed by ER-resident oxidoreductin 1 and protein disulphide isomerase, which facilitate nonnative structural disulphide formation in the secretory pathway (Bulleid and Ellgaard, 2011). First identified in yeast (Delaunay et al., 2002; Fourquet et al., 2008), such proteinmediated redox relays participate in several mammalian signalling pathways. For example, GPX4 transfers its $\mathrm{H}_{2} \mathrm{O}_{2-}$ mediated oxidation to keratin-like proteins to stimulate disulphide bond formation in developing sperm (Maiorino et al., 2005). The first PRX-mediated redox relay was identified in the activation of ASK1. Here PRX1 plays an active and specific disulphide transfer role by facilitating ASK1 dimerisation, such that covalent, but transient, PRX1-ASK1 complexes (but not PRX2-ASK1) were observed upon an increase in ROS (Jarvis et al., 2012). Interestingly, besides explaining the occurrence of oxidation in the cytosol, the redox-relay model might also explain how specific redox signalling can occur through (scaffold-regulated) specific interactions between PRX1 and its target proteins.

\section{CIRCADIAN TIMEKEEPING MECHANISMS DICTATE HOMEOSTASIS}

The term "homeostasis" [homoios (similar) and stasis (standing still)] implies the existence of a biological steady state that is "preferred" and returned to, following a departure; however physiology is not as constant as suggested in some textbooks. Circadian (meaning "about daily") timekeeping mechanisms allow organisms to adapt to the 24-hour daily cycle, allowing them to anticipate, and resonate with, the predictable environmental cycle of day and night (Dunlap, 1999). The mammalian "master clock", resides in the hypothalamic suprachiasmatic nucleus (SCN), where it co-ordinates systemic adaptions to the day-night cycle; timing the temporal orchestration of overt physiology and behaviours, such as sleep/wake (Welsh et al., 2010). It is now well established however, that essentially every cell in the body is possessed with innate circadian timekeeping capacity (Welsh et al., 2004; Yoo et al., 2004). In vivo, these cell-autonomous oscillations are normally synchronised by the timing of endocrine signals, such as glucorticoids, and by other cues such as body temperature rhythms (Mohawk et al., 2012; Saini et al., 2015), but critically cellular circadian rhythms are not dependent upon any extracellular timing signals. Indeed using a bioluminescent reporter (PER2::LUC), under constant conditions, circadian gene expression rhythms in primary mouse fibroblasts were recently shown to persist for longer than a month ex vivo (Leise et al., 2012).

Circadian rhythms permeate mammalian cell biology, with 'omics studies in tissues and isolated cells both revealing that significant proportions of gene expression and metabolism are circadian regulated (Asher and Schibler, 2011; Bass, 2012), with a commensurate impact upon biological function. For example, a recent report by (Zhang et al., 2014) found that more 
than a third of protein-coding genes in the mouse genome exhibit circadian regulation in one or more tissues. In consequence, it should not be surprising that from cell division (Bieler et al., 2014; Feillet et al., 2014; Matsuo et al., 2003) to signal transduction (O'Neill et al., 2008), from inflammation (Gibbs et al., 2014) to neuronal long-term potentiation (Chaudhury et al., 2005), circadian rhythms modulate cellular activity to support anticipated demand. A good example is the upregulation of transcripts and activities associated with gluconeogenesis and glycogenolysis at the beginning of the rest/inactive phase in mouse liver, which maintain blood glucose levels during the daily fast that occurs during sleep (Zhang et al., 2010).

The growing number of reports, discussed below, showing that cellular redox balance is circadian regulated should not come as any shock. Based on the evidence that redox signalling mediates many cellular functions, including the activity of specific transcription factors and metabolic enzymes, it is plausible the converse may also be true: that redox signalling regulates circadian timekeeping. A circadian output that also functions as a circadian input becomes indistinguishable from a core clock mechanism [or zeitnehmer (Roenneberg and Merrow, 2002)]. If cellular redox rhythms do constitute an important part of the circadian clock mechanism, then conceptual advances in both the redox and circadian field could readily be anticipated. In the rest of this review therefore, we wish to appraise the evidence supporting the hypothesis that cellular circadian rhythms reciprocally regulate cellular redox balance. To do so it is necessary to introduce some key paradigms and concepts from circadian research.

\section{INPUTS, OUTPUTS AND MOLECULAR RHYTHMS - SEVERAL COGS IN ONE CLOCK}

In eukaryotes the cell is the simplest level of biological scale that we know to possess circadian timekeeping. Cell biological approaches are therefore of utility for mechanistic investigations The circadian vocabulary has largely developed from concepts based on behavioural and physiological measurements, but can be extended to define timekeeping at the cellular scale. At the organismal level the essential criteria defining a circadian rhythm are that it: persists with an approximately twenty-four hour period under constant conditions; is entrained by relevant external timing cues (zeitgebers, e.g. light, feeding); and is temperature-compensated (Pittendrigh, 1960). Refining this, we employ the term "cellular clock" to describe the complete set of cellular mechanisms and components that are necessary and sufficient to maintain a temperature-compensated $\sim 24 \mathrm{~h}$ oscillation in some biological process, that is sensitive to appropriate extracellular stimuli.

Whilst the functional contribution of assorted "clock genes" towards coordinating circadian physiology at the organismal level is proven beyond reasonable doubt (Bass and Takahashi, 2010), the mammalian cellular clock mechanism is not completely understood at this time. By this we mean that, to our knowledge, no extant hypothesis adequately explains in biochemical detail a causal chain of defined molecular events that give rise to a self-sustained oscillation of circadian period (O'Neill et al., 2013). Great progress has been made, however, in characterising many input signals to, and rhythmic outputs from, the cellular clock. Moreover many of its essential and auxiliary, transcriptional and post-translational components have been identified. The foremost of these are described below.

In the vast majority of contexts and mammalian cell types, several inter-connected delayed Gene Expression Feedback Loops (GEFLs; also known as Transcription-Translation Feedback Loops, TTFLs) regulate circadian gene expression. By binding to promoter regions in diverse clock-controlled genes, and acting in concert with tissue-specific promoters, cycling clock gene activity readily accounts for the majority of gene expression rhythms observed in vivo (Mohawk et al., 2012;

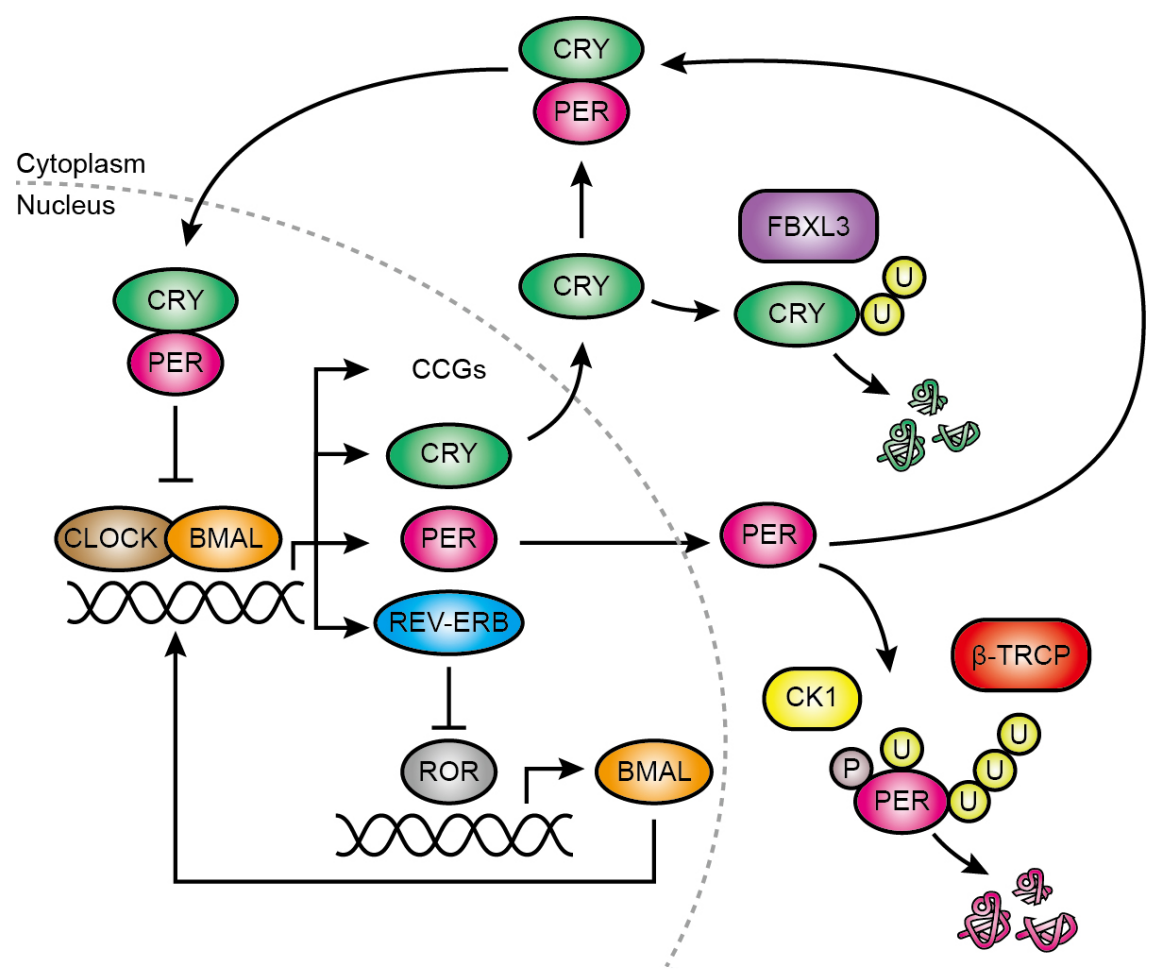

Fig. 3. Models for gene expression feedback loops responsible for circadian gene expression. Simplified representation of the two major gene expression feedback loops. See text for details. CCG, Clock-controlled genes. 
Ueda, 2007; Zhang et al., 2014). The term "clock gene" itself is rather poorly defined, but in the broadest sense could be taken to mean a gene whose expression contributes to the fidelity of circadian timekeeping, and whose gene product directly or indirectly represses its own activity following a lengthy delay, leading to an oscillation in gene expression. As such a gene expression delayed negative feedback loop has been proposed as the essential mechanistic basis of the circadian rhythm in animals (Hardin et al., 1990; Rosbash, 2009) as well as plants and fungi (Dunlap, 1999); although it should be mentioned that the particular clock protein transcription factors identified in each eukaryotic kingdom share no similarity.

In short, the main mammalian GEFL (Fig. 3) begins with the activating bHLH-PAS (basic Helix-Loop-Helix-PER-ARNT-SIM) transcription factors BMAL1 (brain and muscle ARNT-like protein) and CLOCK (circadian locomotor output cycle kaput) or homologue NPAS2 (neuronal PAS-domain containing protein 2). Their activity at E-box promoters results in upregulation of many targets, amongst which are the period (encoding PER1, 2 and 3) and cryptochrome genes (encoding CRY1 and CRY2). PER and CRY proteins gradually accumulate and together form a repressive complex, which eventually is licensed for inhibition of nuclear BMAL1 and CLOCK activity - thereby repressing their own transcription. Due to the time required to assemble sufficient levels of this repressive complex (the negative feedback is delayed), accompanied by extensive daily changes in surrounding chromatin structure and histone modification, an oscillation of PER and CRY proteins (and of other CLOCKBMAL1) target genes, results (Dunlap, 1999; Reppert and Weaver, 2002).

In a secondary loop, the levels of BMAL1 (and other RORregulated genes) are regulated in a circadian fashion. Here, ROR (Retinoic acid-related Orphan Receptor) proteins induce the expression of genes bearing promoter ROR-elements (RORE), including BMAL1. BMAL1 in turn regulates the (rhythmic) expression of REV-ERB proteins, which repress ROR-mediated gene expression by competing for RORE binding, forming another delayed negative feedback.

Important to note, and a repetitive theme in circadian biology, most of the "clock genes" (PER, CRY, BMAL, REV-ERB) may be considered both as inputs and outputs of the cellular clock: they contribute to the organisation of the clock, but also oscillate themselves as a result. Due to the overt oscillations of these proteins and their transcripts, clock gene expression is commonly used as a reporter of the molecular clockwork. In particular, the Bmal1 promoter, the Per2 promoter and the PER2 coding sequence, all coupled with firefly luciferase, are frequently used to measure the period, amplitude and phase of circadian rhythms in cultured cells/tissues and even in freely behaving animals (Saini et al., 2013; Sato et al., 2006; Yoo et al., 2004).

Both of these feedback loops rely on a positive input and a delayed feedback for their persistent oscillatory activity. Compared with the length of a day, transcription and translation of clock genes occurs quickly $(0.25-1 \mathrm{~h}$ following activation), thus in the absence of extensive post-translational regulation, it is difficult to account for the delay constants that generate the slow kinetics of clock gene expression. Indeed, combined microarray and proteomic studies in mouse liver, show PER and CRY protein expression to peak roughly 6 hours later than peak mRNA expression of the same gene (Lee et al., 2001). As might be expected, this delay is predominantly regulated posttranslationally, as overlap of the mRNA peak and ribosomal mRNA loading (Atger et al., 2015; Jang et al., 2015) suggests that translation of the mRNA occurs without any delay. Turnover of the PER and CRY proteins, for example, is tightly regulated by post-translational modifications. In particular CK $1 \delta / \varepsilon$ (casein kinase $1 \delta$ and $\varepsilon$ ) phosphorylates PER2 and target it for $\beta$ TRCP-mediated ubiquitination (Eide et al., 2005; Reischl et al., 2007), resulting in proteosomal degradation. Similarly, CRY is targeted for degradation by FBXL3-mediated ubiquitination (Godinho et al., 2007), which is counteracted by USP7 (HAUSP) (Papp et al., 2015). Interestingly, the PER-CRY binding interface blocks the binding site for FBXL3, and PER binding to CRY thus protects it from degradation (Nangle et al., 2014). In addition to $C K 1 \delta / \varepsilon$, other ubiquitous kinases such as glycogen synthase kinase $3 \beta$ and casein kinase 2 contribute to regulating the stability, activity and subcellular localisation of clock proteins (Maier et al., 2009; O'Neill et al., 2013) which are additionally regulated by a further host of post-translational modifications including acetylation, N-glycosylation and sumoylation (Asher et al., 2008; Cardone et al., 2005; Fogg et al., 2014; Kaasik et al., 2013; Ripperger and Schibler, 2006).

\section{CELLULAR CLOCKS DO NOT REQUIRE (CYCLING) TRANSCRIPTION}

Homozygous deletion of many of the core clock genes results in robust behavioural and cellular circadian phenotypes. These can be classified into three groups: (1) mild phenotype e.g. CLOCK (DeBruyne et al., 2006); (2) short or long period e.g. CRY1 and CRY2 knockout, respectively (Horst and Muijtjens, 1999); (3) no circadian rhythm detected (sometimes described as arrhythmic). In the last group, mice that lack either BMAL, or both CRY proteins, do not exhibit circadian rhythms in behaviour or clock gene transcription (Bunger et al., 2000; Horst and Muijtjens, 1999). These and other transgenic mouse models strongly suggest that the activity of clock proteins is necessary for the expression of normal circadian rhythms. Knockout mice do not demonstrate that clock gene expression is required to cycle per se though. Indeed when clock proteins are constitutively expressed the circadian phenotype is generally mild (Fan et al., 2007; Fujimoto et al., 2006; Okano et al., 2009), although overexpression can show more marked effects (Chen et al., 2009). It is therefore plausible that a certain level of clock protein abundance is simply permissive for normally functioning circadian rhythms, and that their oscillations in abundance play an auxiliary (rather than essential) role in terms of cellular clock mechanism, but do serve to increase the amplitude, robustness and fidelity of the oscillation (Hastings et al., 2008).

In support of this possibility, several observations have suggested that clock gene transcriptional cycles may not be absolutely required for circadian rhythms at the cellular level (O'Neill et al., 2013). For example, Paulose et al. (2012) observed circadian rhythms in glucose metabolism in mouse embryonic stem cells, which lack rhythms in clock gene expression. Similarly, separate groups have observed circadian rhythms in global, and clock protein, translation in isolated human cells, and mouse SCN ex vivo, respectively, that were homozygous null for the "essential" clock gene bmal1 (Ko et al., 2010; Lipton et al., 2015). Also PER2::LUC oscillations were found to persist in around $50 \%$ of SCN slices from mice that lack both CRY proteins the "essential" repressors of the main GEFL (Maywood et al., 2011; Ono et al., 2013). Moreover, inspired by prior experiments performed upon algal and cyanobacterial clocks (Nakajima et al., 2005; O'Neill et al., 2011; Sweeney and Haxo, 1961; Tomita et al., 2005), several groups have now observed circadian rhythms in isolated human and mouse red blood cells. Mammalian erythrocytes lack a nucleus, or any other organelles, and therefore lack the capacity for nascent gene expression. 
Thus the erythrocyte cellular clockwork cannot conceivably rely upon GEFLs. The main marker for erythrocyte rhythms employed in these studies was PRX hyperoxidation (Cho et al., 2014; Homma et al., 2015; O'Neill and Reddy, 2011), which showed a temperature-compensated circadian oscillation that could be entrained by externally applied temperature cycles (mimicking body temperature rhythms). As might be anticipated, the $\mathrm{PRX}-\mathrm{SO}_{2 / 3}$ rhythm was accompanied by a rhythm in total NA(P)DH levels (O'Neill and Reddy, 2011), and was dependent upon SOD1 activity, haemoglobin auto-oxidation and proteasomal degradation (Cho et al., 2014; Homma et al., 2015).

In our opinion though, whilst the evidence that the cellular clock does not absolutely require transcription, cycling or otherwise, has become quite compelling, it is also true that gene expression cycles facilitated by rhythmic clock protein activity play an essential cellular timekeeping role under almost all normal circumstances. Therefore in considering how the cellular clock interacts with redox signalling, we find it unhelpful to arbitrarily apportion timekeeping function between transcriptional and non-transcriptional mechanisms, since both are cogs of the same cellular clockwork and it is unlikely that either alone would sustain a circadian rhythm with any robustness.

\section{CIRCADIAN CONTROL OF THE CELLULAR REDOX STATE}

There is a substantial body of evidence demonstrating that the circadian clock regulates cellular redox state. First indications for this came from studies in the fungus Neurospora crassa, where it was shown that the oxidation state of nicotinamide adenine dinucleotide (the NAD/NADH ratio) exhibits daily rhythms (Brody and Harris, 1973). Subsequent studies in other model systems have also found the redox balance of pyridine nucleotides to be circadian-regulated. For example, nicotinamide adenine dinucleotide phosphate oxidation (NADP/ NADPH) oscillations have been observed in plants (Zhou et al., 2015); protein glutathionylation and flavin adenine nucleotide (FAD)/NADPH oscillate in rodent $\mathrm{SCN}$ ex vivo (Wang and Gillette, 2012); NAD/NADH oscillates in the epidermis of living mice (Stringari et al., 2014); total $\mathrm{NAD}(\mathrm{P}) \mathrm{H}$ oscillates in human erythrocytes (O'Neill and Reddy, 2011); as do total NAD levels in mouse liver and cultured myoblasts (Peek et al, Science, 2013). Besides rhythmic abundance of dinucleotides, recently the oxidation state of PRX proteins have been a useful marker for circadian redox oscillations. In addition to isolated erythrocytes and the alga Ostreococcus tauri, cell-autonomous circadian oscillations in $\mathrm{PRX}-\mathrm{SO}_{2 / 3}$ levels have now been observed in a variety of organisms, cell lines and tissues (Edgar et al., 2012; Kil et al., 2015; O'Neill and Reddy, 2011; O'Neill et al., 2011). The oscillation in $P R X-S_{2 / 3}$ abundance appears to be a cellular clock output only, since PRX activity is not required for cellular circadian rhythms (Causton et al., 2015). Rather it seems likely to be driven by an underlying rhythm in oxidative metabolism (Causton et al., 2015; Hoyle and O'Neill, 2014).

In line with the cellular clock being an important regulator of redox homeostasis, clock mutant mouse models exhibit ROSassociated phenotypes. Most pronounced is the premature ageing phenotype and shortened lifespan of BMAL $1^{-/}$mice, which was partially rescued by life-long administration of the GSH-precursor N-acetyl cysteine (NAC) (Kondratov et al., 2006, 2009). Fibroblasts and other tissues isolated from BMAL $1^{-1-}$ mice exhibit very high ROS loads (Lee et al., 2013a; Musiek et al., 2013), presumably due to another role of BMAL1 as a transcriptional regulator of cellular antioxidant expression via NRF2 (Lee et al., 2013a; Pekovic-Vaughan et al., 2014). Conversely,
$\mathrm{CRY}^{-1-} / \mathrm{CRY} 2^{-1-}$ cells seem to suffer from reductive stress (Jacobi et al., 2015; Peek et al., 2013).

Logically, oscillations in cellular redox state could either result from rhythmic ROS production, or from the rhythmic recycling or rhythmic expression of cellular antioxidant proteins. In fact, all three of these appear to be circadian regulated, as will be exemplified below.

First, cellular metabolism is under circadian control (Bass, 2012). As mitochondrial metabolism is the major source of cellular ROS in most cell types, rhythmic oxidative phosphorylation potentially contributes to cellular redox oscillations (excepting erythrocytes). As long ago as 1972 it was known that oxygen consumption of rat liver cells exhibit circadian oscillations (Langner and Rensing, 1972), suggesting some underlying circadian regulation of metabolic activity. Indeed, circadian oscillations in mitochondrial respiration have been found in mouse liver (Jacobi et al., 2015; Peek et al., 2013), skin (Stringari et al., 2014), and a myotube model (Peek et al., 2013). These oscillations coincide with diurnal BMAL1-dependent oscillations in mitochondrial biogenesis, protein expression and morphology. Liver cells from liver-conditional BMAL $1^{-1-}$ mice show diminished and arrhythmic respiration, swollen mitochondria and an increased ROS load, whereas these phenotypes are partially restored by expression of the fission protein FIS1, suggesting another role for BMAL1 in the regulation of mitochondrial quality control (Jacobi et al., 2015). An additional explanation for this phenotype is found in the circadian regulation of NAD biosynthesis. As well as being an important electron carrier required in glycolysis and the Krebs cycle, NAD functions as a co-factor for several enzymes, among which are the Sirtuin histone (and protein) deacetylase (HDAC) proteins (Vassilopoulos et al., 2011). The rate of NAD production is regulated, in part, by the abundance and activity of nicotinamide phosphoribosyltransferase (NAMPT), which is under transcriptional control the BMAL1:CLOCK complex (Nakahata et al., 2009; Ramsey et al., 2009). The circadian expression of NAMPT is thought to result in circadian abundance of NAD, coinciding with the rhythmic activity of mitochondrial SIRT3 and deacetylation of several SIRT3 targets involved in mitochondrial metabolism (Peek et al., 2013). In addition, nuclear SIRT6 is reported to be affected by NAD oscillations, remodelling chromatin structure to allow BMAL1:CLOCK DNA binding (thereby governing a positive feedback), and recruiting SREBP-1 to regulate the rhythmic expression of proteins involved in fatty acid and cholesterol metabolism (Masri et al., 2014). BMAL1-deficient fibroblasts exhibit reduced NAD levels, reduced oxidative phosphorylation/fatty acid oxidation rates and increased glycolytic rate, which is rescued by pharmacological restoration of NAD levels (Peek et al., 2013). Thus, via several different pathways, the BMAL1:CLOCK complex regulates mitochondrial metabolism and as such, mitochondrial ROS production.

Besides mitochondrial metabolism, NADPH oxidase (NOX) enzymes are implicated in the production of ROS. Clear circadian expression of NOX4 occurs in mouse lung, liver and kidney, for example, peaking in the opposite circadian phase to BMAL1 (CircaDB) (Pizarro et al., 2013). In agreement with this, NOX4 expression is significantly increased in arteries isolated from BMAL1 ${ }^{-/-}$mice, as is the ROS load (Anea et al., 2013). We are not aware of studies directly testing the role of NOX proteins in cellular redox oscillations, but as the phase relationship of NOX4 with BMAL1 is similar to that of the NAD and oxidative phosphorylation peak (Peek et al., 2013), it seems plausible that NOX4 in some tissues contributes to circadian rhythms in ROS production.

Second, in addition to ROS production, cellular antioxidant 
capacity is also circadian regulated. For example, the NAMPTmediated NAD oscillations described above allow for rhythmic activation of the nuclear HDAC function as well as rhythmic regulation of PER2 deacetylation and BMAL1:CLOCK activity (implicating NAD as both in- and outputs of cellular timekeeping) (Asher et al., 2008; Nakahata et al., 2009; Ramsey et al., 2009). SIRT1 in particular is also implicated in the regulation of several non-clock transcription factors. Among these, p53 (Vaziri et al., 2001) and FOXO (Brunet et al., 2004; van der Horst et al., 2004) are important regulators of the cellular redox state (de Keizer et al., 2011; Kruiswijk et al., 2015), and thus allow for circadian control of antioxidant protein expression. The contribution of p53 and FOXO to redox oscillations have yet to be studied to our knowledge, though we appreciate that their explicit contribution may be masked by direct regulation of the antioxidant response by BMAL:CLOCK. E-BOX mediated circadian regulation of NRF2 expression in the lung is required for rhythmic GSH production (Pekovic-Vaughan et al., 2014), and likely a plethora of other antioxidants (Gorrini et al., 2013). Oscillations in NRF2 expression are also found in several other tissues (Pizarro et al., 2013). In liver, a wide array of genes involved in the antioxidant response exhibit diurnal oscillations. Beyond NRF2 and KEAP1, the expression of NRF2 target genes NQO1, SOD1, CAT and GPX all exhibit circadian expression (Xu et al., 2012). NRF2 also regulates the expression of several enzymes involved in NADPH production (Mitsuishi et al., 2012), allowing BMAL1:CLOCK-NRF2 regulation of NADP/ NADPH ratio, and therefore antioxidant recycling. In the brain, NRF2-independent oscillations of ALDH2 and NQO1 are associated with protection from redox-induced neurodegeneration (Musiek et al., 2013).

The above examples for circadian control of cellular redox state involve transcriptional regulation of either ROS or antioxidant production. Circadian oscillations of PRX oxidation (O'Neill and Reddy, 2011) and GSH:GSSG ratio (Radha et al., 1985) however, can occur in the absence of transcriptional cycles, clearly implicating transcription-independent mechanisms in circadian redox control. These remain largely uncharacterised to date, although several biochemical mechanisms have been described that could be relevant. For example, in the adrenal gland, lung, heart and brown adipose tissue, circadian oscillations in oxidation of (mitochondrial) PRX3 are proposed to be regulated through a redox feedback loop involving SRX. Here, mitochondrial ROS induces the oxidation and inactivation of PRX3, allowing $\mathrm{H}_{2} \mathrm{O}_{2}$ to leak into the cytosol. Cytosolic SRX becomes oxidised and forms a complex with HSP90, which allows for the import of SRX into the mitochondria where it reduces PRX3. Because free SRX in the mitochondria is sensitive to LON-mediated degradation, whereas PRX3-bound SRX is protected from this degradation, SRX becomes degraded when its job is done and the cycle begins afresh (Kil et al., 2015). The evidence supporting this sequence of molecular events is compelling, however it remains to be seen whether these oscillations are intrinsic to mitochondrial biology, or are driven by rhythmic cues from the surrounding cellular clockwork.

In summary a strong and growing body of evidence suggests that circadian rhythms in redox balance occur cell-autonomously as well as in vivo, and moreover that circadian disruption can be associated with deregulation of redox homeostasis.

\section{REDOX CONTROL OF GEFL-MEDIATED TIMEKEEPING}

As discussed above, redox signals impinge upon many signal transduction pathways. It is therefore plausible that GEFLmediated timekeeping is also redox-regulated as has been suggested in non-mammalian models. For example, SODdeficiency in Neurospora crassa increases the robustness of overt rhythmicity (Yoshida et al., 2011), and increased ROS concentrations induce shorter circadian period and phase advances. Interestingly, this was very much dependent on the source of ROS, since only metabolically generated ROS had this effect, whereas rhythmic ROS production by NOX did not (Gyöngyösi et al., 2013). Acute manipulation of redox state, e.g. using high extracellular $\mathrm{H}_{2} \mathrm{O}_{2}, \mathrm{GSH}$, or diamide, does affect the phase and period in mammalian cells and cultured SCN (Tamaru et al., 2013; Wang and Gillette, 2012). Such manipulations certainly suggest that the cellular clock is susceptible exogenous oxidative and reductive stresses, but are not sufficient to demonstrate their relevance in the context of normal cellular timekeeping. Thus we are unaware of any convincing demonstration that oscillations in redox balance normally function to regulate circadian rhythms, although the principle that metabolism regulates the cellular clock is generally accepted (Asher and Schibler, 2011). It is the case however, that several possible redox-sensitive clock-relevant regulatory signalling nodes have been identified, as we shall describe.

First, we note that the metabolic oscillations described in the previous section have all been implicated in regulating transcriptional activity of the core clock genes e.g. oscillations in NAD regulate the activity of SIRT1, which in turn regulates PER2 deacetylation and BMAL1:CLOCK activity (Asher et al., 2008; Nakahata et al., 2009; Ramsey et al., 2009). The functional evidence that NAD oscillations make a significant contribution to cellular clock function is rather weak however (Sahar et al., 2011). Thus it remains possible that a certain range of cellular NAD is simply permissive for cellular clock function, and oscillations in steady state NAD levels result simply from a rhythm in consumption.

A second potential route from redox back into the clock is based upon biochemical observations that the affinity of CLOCK:BMAL1 (and NPAS2:BMAL1) heterodimers for DNA Ebox elements is regulated by the redox state of $N A D(P)$ cofactors, being favoured by high $\mathrm{NAD}(\mathrm{P}) \mathrm{H}$, and opposed by high $\operatorname{NAD}(P)$ (Rutter et al., 2001; Yoshii et al., 2015). The biological relevance of these observations are unclear however, since this increased DNA-binding affinity was dependent upon dinucleotide concentrations within the low millimolar range, $>10$-fold higher than best estimates for total nuclear NAD(P)H $(\sim 100$ $\mu \mathrm{M})$ (Zhang et al., 2002). Moreover to elicit circadian regulation of DNA binding would require a substantial oscillation either in ratio of free nuclear $\mathrm{NAD}(\mathrm{P}) \mathrm{H}: \mathrm{NAD}(\mathrm{P})$, or else correctly timed, highly localized production of $\mathrm{NAD}(\mathrm{P}) \mathrm{H}$ in the immediate vicinity of the transcriptional complex. At present we are aware of no evidence supporting either scenario.

Rhythms in PRX oxidation suggest that the oxidation status of other protein-thiols might also oscillate and result, for example, in a concomitant release of KEAP1-NRF2 binding, thereby activating downstream NRF2-mediated antioxidant responses. NRF2 transcriptionally activates REV-ERB $\alpha$ expression (Yang et al., 2014), though the extent to which this contributes to normal circadian regulation of REV-ERB $\alpha$ is unknown. With respect to direct cysteine-mediated regulation of GEFL clock proteins several possible means of redox input have been described.

A recent $\mathrm{x}$-ray crystal structure identified a tightly bound $\mathrm{Zn}^{2+}$ ion at the interface between PER2 and CRY1 (Schmalen et al., 2014). $\mathrm{Zn}^{2+}$ co-ordination was shown to be important for stabilising the PER2-CRY1 complex and was further proposed to facilitate the reduction of a nearby intramolecular disulphide bridge in CRY1. Moreover disulphide formation was shown to 
occur in CRY1 expressed in living cells. Whether or not CRY1 cysteine oxidation oscillates was not reported. A subsequent report by Nangle et al. (2014) confirmed this $\mathrm{Zn}^{2+}$-interface, but reported that Cys=>Ala mutation of the proposed redoxsensitive cysteine had little effect on cellular rhythms. These over-expression studies performed in CRY deficient mouse embryonic fibroblasts do not adequately address the contribution that CRY1 cysteine oxidation may or may not make to the cellular clock, however.

CRY proteins are also regulated by the nutrient-responsive adenosine monophosphate-activated protein kinase (AMPK), with AMPK stimulation leading to CRY phosphorylation and degradation (Lamia et al., 2009). AMPK is negatively regulated by cysteine oxidation in its $\alpha$ subunit and TRX-mediated AMPK reduction is essential for activation of AMPK during energy starvation (Shao et al., 2014). Moreover, CRY1 turnover upon DNA damage is regulated by the deubiquitinase protein USP7/HAUSP (Papp et al., 2015), which contains a redoxsensitive cysteine in its active site, that is inhibited by oxidation (Lee et al., 2013b). Perturbation of either AMPK or USP7 activity affects cellular rhythms, and thus these CRY-regulators introduce, additional plausible means whereby circadian rhythms in redox and metabolism might communicate with the GEFL through its essential CRY repressors. Again however, neither of these possibilities have been explicitly tested.

A further potential redox route into the clockwork lies in a redox-sensitive cysteine within the ligand-binding pocket of another GEFL protein, REV-ERB $\beta$. Both REV-ERB $\alpha$ and $\beta$ are nuclear receptors for the porphyrin haem, such that haem binding activates repressor activity against target genes (Raghuram et al., 2007). Cysteine oxidation abolishes haem-binding in vitro, and has been proposed to act as a "redox switch" in cells. The hypothesis that circadian REV-ERB $\beta$ oxidation feeds into the cellular clock has also not been tested however.

It is also perhaps worth mentioning that although cysteine is a relatively rare amino acid residue ( $2 \%$ content in mammalian proteins), the strongest point mutant circadian phenotypes in vivo and in vitro, with regards the speed at which the clock runs, result from missense mutations that involve a cysteine. A Cys => Ala mutation in CRY1 (Okano et al., 2009), and a Cys $=>$ Ser mutation in its E3 ligase F-box adaptor (FBXL3) (Godinho et al., 2007), both result in circadian periods that are 3-4 hours longer than wild type, whereas an Arg => Cys muta- tion in CK1 $1 \varepsilon$ results in a clock that runs 3-4 h shorter (Lowrey et al., 2000; Meng et al., 2008). Time will tell whether this correlation has any deeper significance.

From these examples it should be clear that whilst several mechanisms have been identified by which cell-autonomous circadian oscillations in redox balance might regulate GEFL activity, a clear demonstration that this actually occurs in mammalian cells is currently lacking.

\section{CONCLUSION}

Taken together, there is good evidence for cellular redox state being circadian regulated. Furthermore phenotypes of clock mutants suggest this has clear implications for systemic redox homeostasis. There are several biochemical indications that changes in cellular redox state may function as a circadian input (zeitgeber) and feedback into the cellular clock mechanism. We are not aware, however, of any compelling demonstration that the latter makes a significant contribution in a mammalian cellular context, let alone that it might be a prerequisite for cellular timekeeping. Therefore whilst it is most plausible that redox modulation of the cellular clock takes place, we think it is premature to conclude there is an important role for redox signalling in the mammalian cellular clock.

For redox oscillations to be considered as a mammalian cellular clock mechanism, as has $\mathrm{Ca}^{2+} / \mathrm{cAMP}$-signalling (O'Neill and Reddy, 2012), it must be shown that: (1) a specific redox couple oscillates in a variety of cellular models; (2) that appropriate manipulation of this redox couple is sufficient to determine the phase, amplitude and period of cellular rhythms; and (3) that specific transduction pathways communicate cyclical redox signals to regulate GEFL function.

To approach the biological significance of redox control of the clock, we also need to understand the molecular underpinnings of PRX-SO $\mathrm{S}_{2 / 3}$ oscillations - what is the timing mechanism that drives them? This question could be answered more readily with robust post-translational reporters for redox balance and ROS levels (Ezerina et al., 2014), rather than indirect markers such as $\mathrm{PRX}-\mathrm{SO}_{2 / 3}$. In addition more sophisticated genetic tools are required than gene knockout. For example, SOD1 knockout does not affect timekeeping in mice (Homma et al., 2015). Is this because regulated ROS production is not relevant to circadian timekeeping or because compensatory mechanisms (e.g. in-

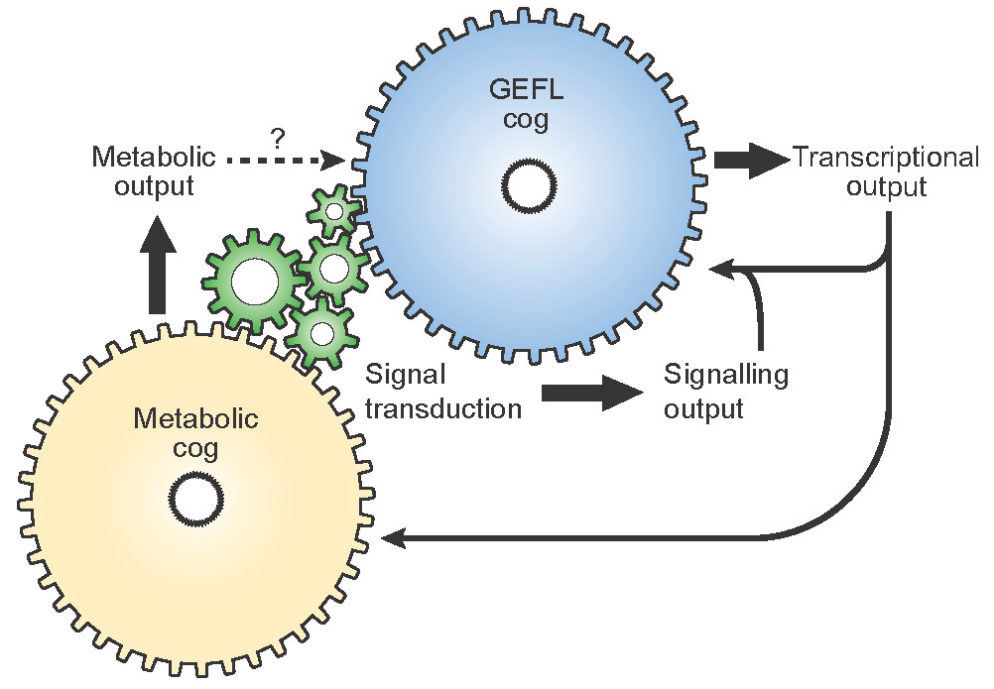

Fig. 4. The role of GEFLs and metabolic oscillations in cellular timekeeping - multiple cogs in one clock. Cellular timekeeping involves several interconnected molecular systems, which are functionally interdependent under the vast majority of circumstances. At the level of the individual cell, there is no evidence for the existence of multiple clocks. It may instead be appropriate to consider the contribution that different cogs make to a single cellular clock mechanism. Some teeth of each cog make essential contributions to cellular clock function whereas others are auxiliary and/or mediate celltype specific clock outputs. In addition, some cellular mechanisms, such as ATP generation for example, may simply be permissive for the cellular clock to tick rather than being a state variable of the oscillation. 
creased SOD2) are employed? Inducible expression/repression models would be of great utility here.

Furthermore, it has not been strictly established that redox balance needs to oscillate for the cellular clock to function. Might there instead simply be a permissive range where cellular clocks operate? Indeed a similar argument has been made for BMAL1-deficient mice and tissues (Musiek, 2015; Musiek et al., 2013) i.e. it is plausible that BMAL1 abundance does not need to oscillate as such; rather that sufficient BMAL1 is required to activate antioxidant expression, and without BMAL1 cells succumb to chronic oxidative stress, outside the redox range where the cellular clock can function.

Until these issues have been resolved, we feel it inadvisable to use terms such as "redox oscillator" or "redox clock" since these phrases imply self-sufficiency. Until the underlying mechanism and mode(s) of coupling with GEFLs are firmly established it remains possible that circadian cycles of redox balance are exclusively clock outputs. If metaphors are required, we suggest that the image of a "metabolic cog" normally enmeshed with GEFLs, within the more complex cellular circadian machinery might suffice (Fig. 4). Indeed similarly, we are not aware of any evidence that a minimally reconstituted GEFL would be intrinsically circadian, as has been shown by in vitro reconstitution for the entirely post-translational circadian rhythm in the cyanobacteria Synechococcus elongatus (Nakajima et al., 2005).

Even without understanding the detailed molecular underpinnings to circadian regulation of the cellular redox state, it is interesting to speculate about the functional consequences that redox oscillations might have upon normal cell signalling (Fig. 4). Just as the clock impacts upon cellular function through regulating the abundance of many key proteins involved in signal transduction and metabolic pathways (Mauvoisin et al., 2014; Robles et al., 2014), so might circadian rhythms in redox balance impact upon redox-sensitive signalling and metabolism. In mice and humans, for example, it has long been believed that synthesis/secretion of corticosteroids in the adrenal cortex are primarily regulated by circadian signaling from the $\mathrm{SCN}$, through the hypothalamus-pituitary-adrenal (HPA) neuroendocrine axis. Recently however, (Kil et al., 2012) reported that circadian corticosterone production is accompanied by circadian oscillations in PRX3 and SRX abundance, that were required to protect the cell from increased mitochondrial ROS generation due to steroidogenesis during the latter half of the rest/sleep phase. In steroidogenic tissue-specific SRX-deficient mice, the circadian rhythm of adrenal corticosterone production was suppressed: severely blunting an important systemic cue that normally primes animal physiology for the active/wake phase.

Finally, of course it is quite plausible that circadian rhythms in redox may impact upon the efficacy of redox relay signalling (Jarvis et al., 2012), leading to the possibility that oxidation rhythms exist in other important redox-regulated cytosolic proteins such as GAPDH, KEAP1/NRF2, FOXO, ASK1, PKA, PKG, PTEN, PTP1B etc. If validated this would have far reaching, and potentially translational, consequences for the ways in which we understand the circadian clock machinery to interact with other cellular systems.

In conclusion, there exists great potential for cross fertilisation between research into redox signalling and circadian rhythms. From a basic research perspective it is of prime importance to establish explicitly whether crosstalk occurs bidirectionally and its mechanism(s), but this constitutes no barrier to investigating whether the cell interprets a redox signal differently, depending upon the (biological) time of day.

\section{ACKNOWLEDGMENTS}

We wish to thank Jo Westmoreland of LMB Visual Aids. JON is supported by the Medical Research Council (MC_UP_1201/4) and the Wellcome Trust (093734/Z/10/Z). MP is funded by KWF BUIT 2014-6637. We apologise to the many colleagues whose work we did not discuss due to limitations of time and space.

\section{REFERENCES}

Abate, C., Patel, L., Rauscher, F.J., and Curran, T. (1990). Redox regulation of fos and jun DNA-binding activity in vitro. Science 249, 1157-1161.

Anea, C.B., Zhang, M., Chen, F., Ali, M.I., Hart, C.M.M., Stepp, D.W. Kovalenkov, Y.O., Merloiu, A.-M., Pati, P., Fulton, D., et al. (2013). Circadian clock control of Nox4 and reactive oxygen species in the vasculature. PLoS One 8, e78626.

Aon, M. a., Cortassa, S., Marbán, E., and O'Rourke, B. (2003). Synchronized whole cell oscillations in mitochondrial metabolism triggered by a local release of reactive oxygen species in cardiac myocytes. J. Biol. Chem. 278, 44735-44744.

Asher, G., and Schibler, U. (2011). Crosstalk between components of circadian and metabolic cycles in mammals. Cell Metab. 13, 125-137.

Asher, G., Gatfield, D., Stratmann, M., Reinke, H., Dibner, C., Kreppel, F., Mostoslavsky, R., Alt, F.W., and Schibler, U. (2008) SIRT1 regulates circadian clock gene expression through PER2 deacetylation. Cell 134, 317-328.

Atger, F., Gobet, C., Marquis, J., Martin, E., Wang, J., Weger, B., Lefebvre, G., Descombes, P., Naef, F., and Gachon, F. (2015) Circadian and feeding rhythms differentially affect rhythmic mRNA transcription and translation in mouse liver. Proc. Natl. Acad. Sci. USA 112, E6579-88.

Bass, J. (2012). Circadian topology of metabolism. Nature 491, 348-356.

Bass, J., and Takahashi, J.S. (2010). Circadian integration of metabolism and energetics. Science 330, 1349-1354.

Bieler, J., Cannavo, R., Gustafson, K., Gobet, C., Gatfield, D., and Naef, F. (2014). Robust synchronization of coupled circadian and cell cycle oscillators in single mammalian cells. Mol. Syst. Biol. 10, 739 .

Bindoli, A., and Rigobello, M.P. (2012). Principles in redox signaling: from chemistry to functional significance. Antioxid. Redox Signal. 18, 1-97.

Brody, S., and Harris, S. (1973). Circadian rhythms in neurospora: spatial differences in pyridine nucleotide levels. Science 180 498-500

Brunet, A., Sweeney, L.B., Sturgill, J.F., Chua, K.F., Greer, P.L., Lin, Y., Tran, H., Ross, S.E., Mostoslavsky, R., Cohen, H.Y., et al. (2004). Stress-dependent regulation of FOXO transcription factors by the SIRT1 deacetylase. Science 303, 2011-2015.

Bulleid, N.J., and Ellgaard, L. (2011). Multiple ways to make disulfides. Trends Biochem. Sci. 36, 485-492.

Bunger, M.K., Wilsbacher, L.D., Moran, S.M., Clendenin, C., Radcliffe, L. a., Hogenesch, J.B., Simon, M.C., Takahashi, J.S. and Bradfield, C. a. (2000). Mop3 is an essential component of the master circadian pacemaker in mammals. Cell 103, 10091017.

Burgoyne, J.R., Madhani, M., Cuello, F., Charles, R.L., Brennan, J.P., Schröder, E., Browning, D.D., and Eaton, P. (2007) Cysteine redox sensor in PKGla enables oxidant-induced activation. Science 317, 1393-1397.

Burgoyne, J.R., Rudyk, O., Cho, H., Prysyazhna, O., Hathaway, N., Weeks, A., Evans, R., Ng, T., Schröder, K., Brandes, R.P., et al. (2015). Deficient angiogenesis in redox-dead Cys17Ser PKARl $\alpha$ knock-in mice. Nat. Commun. 6, 7920.

Cardone, L., Hirayama, J., Giordano, F., Tamaru, T., Palvimo, J., and Sassone-Corsi, P. (2005). Circadian clock control by SUMOylation of BMAL1. Science 309, 1390-1394.

Causton, H.C., Feeney, K.A., Ziegler, C.A., and O'Neill, J.S. (2015). Metabolic cycles in yeast share features conserved among circadian rhythms. Curr. Biol. 25, 1056-1062.

Chang, T.-S., Jeong, W., Woo, H.A., Lee, S.M., Park, S., and Rhee, S.G. (2004). Characterization of mammalian sulfiredoxin and its 
reactivation of hyperoxidized peroxiredoxin through reduction of cysteine sulfinic acid in the active site to cysteine. J. Biol. Chem. 279, 50994-51001.

Chaudhury, D., Wang, L.M., and Colwell, C.S. (2005). Circadian regulation of hippocampal long-term potentiation. J. Biol. Rhythms 20, 225-236.

Chen, R., Schirmer, A., Lee, Y., Lee, H., Kumar, V., Yoo, S.-H., Takahashi, J.S., and Lee, C. (2009). Rhythmic PER abundance defines a critical nodal point for negative feedback within the circadian clock mechanism. Mol. Cell 36, 417-430.

Cho, C.S., Yoon, H.J., Kim, J.Y., Woo, H.A., and Rhee, S.G. (2014) Circadian rhythm of hyperoxidized peroxiredoxin II is determined by hemoglobin autoxidation and the 20S proteasome in red blood cells. Proc. Natl. Acad. Sci. USA 111, 12043-12048.

Cotto-Rios, X.M., Békés, M., Chapman, J., Ueberheide, B., and Huang, T.T. (2012). Deubiquitinases as a signaling target of oxidative stress. Cell Rep. 2, 1-10.

Cremers, C.M., and Jakob, U. (2013). Oxidant sensing by reversible disulfide bond formation. J. Biol. Chem. 288, 2648926496.

Czech, M.P., Lawrence, J.C., and Lynn, W.S. (1974). Evidence for the involvement of sulfhydryl oxidation in the regulation of fat cell hexose transport by insulin. Proc. Natl. Acad. Sci. USA 71, 4173-4177.

Dansen, T.B., Smits, L.M.M., van Triest, M.H., de Keizer, P.L.J., van Leenen, D., Koerkamp, M.G., Szypowska, A., Meppelink, A., Brenkman, A.B., Yodoi, J., et al. (2009). Redox-sensitive cysteines bridge p300/CBP-mediated acetylation and FoxO4 activity. Nat. Chem. Biol. 5, 664-672.

DeBruyne, J.P., Noton, E., Lambert, C.M., Maywood, E.S., Weaver D.R., and Reppert, S.M. (2006). A clock shock: mouse CLOCK is not required for circadian oscillator function. Neuron $50,465-$ 477.

Delaunay, A., Pflieger, D., Barrault, M.B., Vinh, J., and Toledano, M.B. (2002). A thiol peroxidase is an $\mathrm{H} 2 \mathrm{O} 2$ receptor and redoxtransducer in gene activation. Cell 111, 471-481.

Dickinson, B.C. (2015). Plugging the leak Synergistic MRSA combinations. Nat. Publ. Gr. 11, 831-832.

Dunlap, J.C. (1999). Molecular bases for circadian clocks. Cell 96, 271-290.

Edgar, R.S., Green, E.W., Zhao, Y., van Ooijen, G., Olmedo, M., Qin, X., Xu, Y., Pan, M., Valekunja, U.K., Feeney, K.A., et al. (2012). Peroxiredoxins are conserved markers of circadian rhythms. Nature 485, 459-464.

Eide, E.J., Woolf, M.F., Kang, H., Woolf, P., Hurst, W., Camacho, F., Vielhaber, E.L., Giovanni, A., and Virshup, D.M. (2005). Control of mammalian circadian rhythm by CKlepsilon-regulated proteasome-mediated PER2 degradation. Mol. Cell. Biol. 25, 2795-2807.

Ezerina, D., Morgan, B., and Dick, T.P. (2014). Imaging dynamic redox processes with genetically encoded probes. J. Mol. Cell. Cardiol. 73, 43-49.

Fan, Y., Hida, A., Anderson, D. a., Izumo, M., and Johnson, C.H. (2007). Cycling of CRYPTOCHROME proteins is not necessary for circadian-clock function in mammalian fibroblasts. Curr. Biol. 17, 1091-1100.

Feillet, C., Krusche, P., Tamanini, F., Janssens, R.C., Downey, M.J., Martin, P., Teboul, M., Saito, S., Levi, F. a., Bretschneider, T., et al. (2014). Phase locking and multiple oscillating attractors for the coupled mammalian clock and cell cycle. Proc. Natl. Acad. Sci. USA 111, 9828-9833.

Fogg, P.C.M., O'Neill, J.S., Dobrzycki, T., Calvert, S., Lord, E.C., McIntosh, R.L.L., Elliott, C.J.H., Sweeney, S.T., Hastings, M.H., and Chawla, S. (2014). Class Ila histone deacetylases are conserved regulators of circadian function. J. Biol. Chem. 289, 34341-34348.

Fourquet, S., Huang, M.E., D'Autreaux, B., and Toledano, M.B. (2008). The dual functions of thiol-based peroxidases in $\mathrm{H} 2 \mathrm{O} 2$ scavenging and signaling. Antioxid. Redox Signal. 10, 15651576.

Fujimoto, Y., Yagita, K., and Okamura, H. (2006). Does mPER2 protein oscillate without its coding mRNA cycling?: posttranscriptional regulation by cell clock. Genes Cells 11, 525-530.

Gibbs, J., Ince, L., Matthews, L., Mei, J., Bell, T., Yang, N., Saer, B., Begley, N., Poolman, T., Pariollaud, M., et al. (2014). An epithelial circadian clock controls pulmonary inflammation and glucocorticoid action. Nat. Med. 20,919-926.

Godinho, S.I.H., Maywood, E.S., Shaw, L., Tucci, V., Barnard, A.R., Busino, L., Pagano, M., Kendall, R., Quwailid, M.M., Romero, M.R., et al. (2007). The after-hours mutant reveals a role for Fbxl3 in determining mammalian circadian period. Science 316 , 897-900

Goldman, R., Stoyanovsky, D. a, Day, B.W., and Kagan, V.E. (1995) Reduction of phenoxyl radicals by thioredoxin results in selective oxidation of its $\mathrm{SH}$-groups to disulfides. An antioxidant function of thioredoxin. Biochemistry 34, 4765-4772.

Gorrini, C., Harris, I.S., and Mak, T.W. (2013). Modulation of oxidative stress as an anticancer strategy. Nat. Rev. Drug Discov. 12, 931-947.

Grek, C.L., Zhang, J., Manevich, Y., Townsend, D.M., and Tew, K.D. (2013). Causes and consequences of cysteine Sglutathionylation. J. Biol. Chem. 288, 26497-26504.

Gyöngyösi, N., Nagy, D., Makara, K., Ella, K., and Káldi, K. (2013). Reactive oxygen species can modulate circadian phase and period in Neurospora crassa. Free Radic. Biol. Med. 58, 134143.

Hanschmann, E.-M., Godoy, J.R., Berndt, C., Hudemann, C., and Lillig, C.H. (2013). Thioredoxins, glutaredoxins, and peroxiredoxins--molecular mechanisms and health significance: from cofactors to antioxidants to redox signaling. Antioxid. Redox Signal. 19, 1539-1605.

Hardin, P.E., Hall, J.C., and Rosbash, M. (1990). Feedback of the Drosophila period gene product on circadian cycling of its messenger RNA levels. Nature 343, 536-540.

Hastings, M.H., Maywood, E.S., and O'Neill, J.S. (2008). Cellular circadian pacemaking and the role of cytosolic rhythms. Curr. Biol. 18, R805-R815.

Hayes, J.D., and Dinkova-Kostova, A.T. (2014). The Nrf2 regulatory network provides an interface between redox and intermediary metabolism. Trends Biochem. Sci. 39, 199-218.

Homma, T., Okano, S., Lee, J., Ito, J., Otsuki, N., Kurahashi, T., Kang, E.S., Nakajima, O., and Fujii, J. (2015). SOD1 deficiency induces the systemic hyperoxidation of peroxiredoxin in the mouse. Biochem. Biophys. Res. Commun. 463, 1040-1046.

Horst, G.T.J. Van Der, and Muiijjens, M. (1999). Mammalian Cry1 and Cry2 are essential for maintenance of circadian rhythms. $3495,627-630$

Van der Horst, A., Tertoolen, L.G.J., de Vries-Smits, L.M.M., Frye, R. a, Medema, R.H., and Burgering, B.M.T. (2004). FOXO4 is acetylated upon peroxide stress and deacetylated by the longevity protein hSir2(SIRT1). J. Biol. Chem. 279, 2887328879.

Hoyle, N.P., and O'Neill, J.S. (2014). Oxidation-reduction cycles of peroxiredoxin proteins and nontranscriptional aspects of timekeeping. Biochemistry 54, 184-193.

Jacobi, D., Liu, S., Burkewitz, K., Kory, N., Knudsen, N.H., Alexander, R.K., Unluturk, U., Li, X., Kong, X., Hyde, A.L., et al. (2015). Hepatic Bmal1 regulates rhythmic mitochondrial dynamics and promotes metabolic fitness. Cell Metab. 22, 709720.

Jang, C., Lahens, N.F., Hogenesch, J.B., and Sehgal, A. (2015). Ribosome profiling reveals an important role for translational control in circadian gene expression. Genome Res. 25, 18361847

Jarvis, R.M., Hughes, S.M., and Ledgerwood, E.C. (2012). Peroxiredoxin 1 functions as a signal peroxidase to receive, transduce, and transmit peroxide signals in mammalian cells. Free Radic. Biol. Med. 53, 1522-1530.

Kaasik, K., Kivimäe, S., Allen, J.J.J., Chalkley, R.J.J., Huang, Y., Baer, K., Kissel, H., Burlingame, A.L.L., Shokat, K.M.M., Ptáček, L.J.J., et al. (2013). Glucose sensor O-GlcNAcylation coordinates with phosphorylation to regulate circadian clock. Cell Metab. 17, 291-302

De Keizer, P.L.J., Burgering, B.M.T., and Dansen, T.B. (2011) Forkhead box $\mathrm{O}$ as a sensor, mediator, and regulator of redox signaling. Antioxid. Redox Signal. 14, 1093-1106.

Kil, I.S., Lee, S.K., Ryu, K.W., Woo, H.A., Hu, M.C., Bae, S.H., and Rhee, S.G. (2012). Feedback Control of Adrenal Steroidogenesis via H2O2-Dependent, Reversible Inactivation of Peroxiredoxin III in Mitochondria. Mol. Cell 46, 584-594.

Kil, I.S., Ryu, K.W., Lee, S.K., Kim, J.Y., Chu, S.Y., Kim, J.H., Park, S., and Rhee, S.G. (2015). Circadian Oscillation of Sulfiredoxin 
in the Mitochondria. Mol. Cell 59,651-663.

Ko, C.H., Yamada, Y.R., Welsh, D.K., Buhr, E.D., Liu, A.C., Zhang, E.E. Ralph, M.R., Kay, S. a, Forger, D.B., and Takahashi, J.S (2010). Emergence of noise-induced oscillations in the central circadian pacemaker. PLoS Biol. 8, e1000513.

Kondratov, R. V., Kondratova, A. a., Gorbacheva, V.Y., Vykhovanets, O. V., and Antoch, M.P. (2006). Early aging and age-related pathologies in mice deficient in BMAL1, the core component of the circadian clock. Genes Dev. 20,1868-1873.

Kondratov, R. V., Vykhovanets, O., Kondratova, A. a., and Antoch, M.P. (2009). Antioxidant N-acetyl-L-cysteine ameliorates symptoms of premature aging associated with the deficiency of the circadian protein BMAL1. Aging 1,979-987.

Kruiswijk, F., Labuschagne, C.F., and Vousden, K.H. (2015). p53 in survival, death and metabolic health: a lifeguard with a licence to kill. Nat. Rev. Mol. Cell Biol. 16, 393-405.

Kulathu, Y., Garcia, F.J., Mevissen, T.E.T., Busch, M., Arnaudo, N., Carroll, K.S., Barford, D., and Komander, D. (2013). Regulation of A20 and other OTU deubiquitinases by reversible oxidation. Nat. Commun. 4, 1569.

Lamia, K. a, Sachdeva, U.M., DiTacchio, L., Williams, E.C., Alvarez, J.G., Egan, D.F., Vasquez, D.S., Juguilon, H., Panda, S., Shaw, R.J., et al. (2009). AMPK regulates the circadian clock by cryptochrome phosphorylation and degradation. Science 326 , 437-440.

Langner, R., and Rensing, L. (1972). Circadian rhythm of oxygen consumption in rat liver suspension culture: changes of pattern. Z. Naturforsch. B. 27, 1117-1118.

Lee, S.-R., Kwon, K.S., Kim, S.R., and Rhee, S.G. (1998). Reversible Inactivation of Protein-tyrosine Phosphatase 1B in A431 Cells Stimulated with Epidermal Growth Factor. J. Biol. Chem. 273, 15366-15372.

Lee, C., Etchegaray, J.P., Cagampang, F.R., Loudon, a S., and Reppert, S.M. (2001). Posttranslational mechanisms regulate the mammalian circadian clock. Cell 107, 855-867.

Lee, J., Moulik, M., Fang, Z., Saha, P., Zou, F., Xu, Y., Nelson, D.L., Ma, K., Moore, D.D., and Yechoor, V.K. (2013a). Bmal1 and $\beta$ cell clock are required for adaptation to circadian disruption, and their loss of function leads to oxidative stress-induced $\beta$-cell failure in mice. Mol. Cell. Biol. 33, 2327-2338.

Lee, J.-G., Baek, K., Soetandyo, N., and Ye, Y. (2013b). Reversible inactivation of deubiquitinases by reactive oxygen species in vitro and in cells. Nat. Commun. 4,1568.

Leise, T.L., Wang, C.W., Gitis, P.J., and Welsh, D.K. (2012). Persistent cell-autonomous circadian oscillations in fibroblasts revealed by six-week single-cell imaging of PER2::LUC bioluminescence. PLoS One 7, e33334.

Lipton, J.O., Yuan, E.D., Boyle, L.M., Ebrahimi-Fakhari, D., Kwiatkowski, E., Nathan, A., Güttler, T., Davis, F., Asara, J.M. and Sahin, M. (2015). The circadian protein BMAL1 regulates translation in response to S6K1-mediated phosphorylation. Cell 161, 1138-1151.

Lowrey, P.L., Shimomura, K., Antoch, M.P., Yamazaki, S., Zemenides, P.D., Ralph, M.R., Menaker, M., and Takahashi, J.S. (2000). Positional syntenic cloning and functional characterization of the mammalian circadian mutation tau. Science 288, 483-492.

Maier, B., Wendt, S., Vanselow, J.T., Wallach, T., Reischl, S., Oehmke, S., Schlosser, A., and Kramer, A. (2009). A large-scale functional RNAi screen reveals a role for CK2 in the mammalian circadian clock. Genes Dev. 23, 708-718.

Maiorino, M., Roveri, A., Benazzi, L., Bosello, V., Mauri, P., Toppo, S., Tosatto, S.C.E., and Ursini, F. (2005). Functional interaction of phospholipid hydroperoxide glutathione peroxidase with sperm mitochondrion-associated cysteine-rich protein discloses the adjacent cysteine motif as a new substrate of the selenoperoxidase. J. Biol. Chem. 280, 38395-38402.

Masri, S., Rigor, P., Cervantes, M., Ceglia, N., Sebastian, C., Xiao, C., Roqueta-Rivera, M., Deng, C., Osborne, T.F., Mostoslavsky, R., et al. (2014). Partitioning circadian transcription by SIRT6 leads to segregated control of cellular metabolism. Cell 158, 659-672.

Matsuo, T., Yamaguchi, S., Mitsui, S., Emi, A., Shimoda, F., and Okamura, H. (2003). Control mechanism of the circadian clock for timing of cell division in vivo. Science 302, 255-259.

Mauvoisin, D., Wang, J., Jouffe, C., Martin, E., Atger, F., Waridel, P.,
Quadroni, M., Gachon, F., and Naef, F. (2014). Circadian clockdependent and -independent rhythmic proteomes implement distinct diurnal functions in mouse liver. Proc. Natl. Acad. Sci. U SA 111, 167-172.

Maywood, E.S., Chesham, J.E., Brien, J.A.O., and Hastings, M.H. (2011). A diversity of paracrine signals sustains molecular circadian cycling in suprachiasmatic nucleus circuits. Proc. Natl. Acad. Sci. USA 108, 14306-14311.

McCord, J.M., and Fridovich, I. (1969). Superoxide dismutase: and enzymatic function for erythrocuprein (hemocuprein). J. Biol. Chem. 244, 6049-6055.

Meng, Q.-J., Logunova, L., Maywood, E.S., Gallego, M., Lebiecki, J., Brown, T.M., Sládek, M., Semikhodskii, A.S., Glossop, N.R.J., Piggins, H.D., et al. (2008). Setting clock speed in mammals: the CK1 epsilon tau mutation in mice accelerates circadian pacemakers by selectively destabilizing PERIOD proteins. Neuron 58, 78-88.

Mitsuishi, Y., Taguchi, K., Kawatani, Y., Shibata, T., Nukiwa, T., Aburatani, H., Yamamoto, M., and Motohashi, H. (2012). Nrf2 redirects glucose and glutamine into anabolic pathways in metabolic reprogramming. Cancer Cell 22, 66-79.

Mohawk, J. a., Green, C.B., and Takahashi, J.S. (2012). Central and peripheral circadian clocks in mammals. Annu. Rev. Neurosci. 35, 445-462

Monteiro, H.P., and Stern, A. (1996). Redox modulation of tyrosine phosphorylation-dependent signal transduction pathways. Free Radic. Biol. Med. 21, 323-333.

Musiek, E.S. (2015). Circadian clock disruption in neurodegenerative diseases: cause and effect? Front Pharmacol. 6, 29

Musiek, E.S., Lim, M.M., Yang, G., Bauer, A.Q., Qi, L., Lee, Y., Roh, J.H., Ortiz-gonzalez, X., Dearborn, J.T., Culver, J.P., et al. (2013) Circadian clock proteins regulate neuronal redox homeostasis and neurodegeneration. J. Clin. Invest. 123, 5389-5400

Nadeau, P.J., Charette, S.J., Toledano, M.B., and Landry, J. (2007) Disulfide Bond-mediated multimerization of Ask1 and its reduction by thioredoxin-1 regulate $\mathrm{H}(2) \mathrm{O}(2)$-induced c-Jun $\mathrm{NH}(2)$-terminal kinase activation and apoptosis. Mol. Biol. Cell 18, 3903-3913.

Nagy, P., Karton, A., Betz, A., Peskin, A.V, Pace, P., O'Reilly, R.J., Hampton, M.B., Radom, L., and Winterbourn, C.C. (2011) Model for the exceptional reactivity of peroxiredoxins 2 and 3 with hydrogen peroxide: a kinetic and computational study. J. Biol. Chem. 286, 18048-18055.

Nakahata, Y., Sahar, S., Astarita, G., Kaluzova, M., and SassoneCorsi, P. (2009). Circadian control of the $\mathrm{NAD}^{+}$salvage pathway by CLOCK-SIRT1. Science 324, 654-657.

Nakajima, M., Imai, K., Ito, H., Nishiwaki, T., Murayama, Y., Iwasaki, H., Oyama, T., and Kondo, T. (2005). Reconstitution of circadian oscillation of cyanobacterial KaiC phosphorylation in vitro. Science 308, 414-415.

Nangle, S.N., Rosensweig, C., Koike, N., Tei, H., Takahashi, J.S., Green, C.B., and Zheng, N. (2014). Molecular assembly of the period-cryptochrome circadian transcriptional repressor complex. Elife 15, e30674.

O'Neill, J.S., and Reddy, A.B. (2011). Circadian clocks in human red blood cells. Nature 469, 498-503.

O'Neill, J.S., and Reddy, A.B. (2012). The essential role of cAMP / $\mathrm{Ca}^{2+}$ signalling in mammalian circadian timekeeping. Biochem. Soc. Trans 40, 44-50.

O'Neill, J.S., Maywood, E.S., Chesham, J.E., Takahashi, J.S., and Hastings, M.H. (2008). cAMP-dependent signaling as a core component of the mammalian circadian pacemaker. Science 320, 949-953.

O'Neill, J.S., Ooijen, G. Van, Dixon, L.E., Troein, C., Corellou, F., Bouget, F.-Y., Reddy, A.B., Millar, A.J., and van Ooijen, G. (2011) Circadian rhythms persist without transcription in a eukaryote. Nature 469, 554-558.

O'Neill, J.S., Maywood, E.S., and Hastings, M.H. (2013). Cellular mechanisms of circadian pacemaking: beyond transcriptional loops. Handb. Exp. Pharmacol. 2013, 67-103.

Okano, S., Akashi, M., Hayasaka, K., and Nakajima, O. (2009). Unusual circadian locomotor activity and pathophysiology in mutant CRY1 transgenic mice. Neurosci. Lett. 451, 246-251.

Ono, D., Honma, S., and Honma, K. (2013). Cryptochromes are critical for the development of coherent circadian rhythms in the 
mouse suprachiasmatic nucleus. Nat Commun 4, 1666.

Papp, S.J., Huber, A.-L., Jordan, S.D., Kriebs, A., Nguyen, M., Moresco, J.J., Yates, J.R., and Lamia, K.A. (2015). DNA damage shifts circadian clock time via Hausp-dependent Cry1 stabilization. Elife 4, doi: 10.7554/eLife.04883.

Paulose, J.K., Rucker, E.B., and Cassone, V.M. (2012). Toward the beginning of time: circadian rhythms in metabolism precede rhythms in clock gene expression in mouse embryonic stem cells. PLoS One 7, e49555.

Peek, C.B., Affinati, A.H., Ramsey, K.M., Kuo, H.-Y., Yu, W., Sena, L. a, Ilkayeva, O., Marcheva, B., Kobayashi, Y., Omura, C., et al. (2013). Circadian clock NAD+ cycle drives mitochondrial oxidative metabolism in mice. Science 342, 1243417.

Pekovic-Vaughan, V., Gibbs, J., Yoshitane, H., Yang, N., Pathiranage, D., Guo, B., Sagami, A., Taguchi, K., Bechtold, D., Loudon, A., et al. (2014). The circadian clock regulates rhythmic activation of the NRF2/glutathione-mediated antioxidant defense pathway to modulate pulmonary fibrosis. Genes Dev. 28, 548560.

Peralta, D., Bronowska, A.K., Morgan, B., Dóka, É., Van Laer, K., Nagy, P., Gräter, F., and Dick, T.P. (2015). A proton relay enhances $\mathrm{H} 2 \mathrm{O} 2$ sensitivity of GAPDH to facilitate metabolic adaptation. Nat. Chem. Biol. 11, 156-163.

Peskin, A.V., Low, F.M., Paton, L.N., Maghzal, G.J., Hampton, M.B., and Winterbourn, C.C. (2007). The high reactivity of peroxiredoxin 2 with $\mathrm{H}(2) \mathrm{O}(2)$ is not reflected in its reaction with other oxidants and thiol reagents. J. Biol. Chem. 282, 1188511892.

Pittendrigh, C.S. (1960). Circadian rhythms and the circadian organization of living systems. Cold Spring Harb. Symp. Quant. Biol. 25, 159-184.

Pizarro, A., Hayer, K., Lahens, N.F., and Hogenesch, J.B. (2013). CircaDB: A database of mammalian circadian gene expression profiles. Nucleic Acids Res. 41, D1009-1013.

Prysyazhna, O., Rudyk, O., and Eaton, P. (2012). Single atom substitution in mouse protein kinase $G$ eliminates oxidant sensing to cause hypertension. Nat. Med. 18, 286-290.

Putker, M., Madl, T., Vos, H.R.R., de Ruiter, H., Visscher, M., van den Berg, M.C.W., Kaplan, M., Korswagen, H.C.C., Boelens, R., Vermeulen, M., et al. (2013). Redox-dependent control of FOXO/DAF-16 by transportin-1. Mol. Cell 49, 730-742.

Putker, M., Vos, H.R., and Dansen, T.B. (2014a). Intermolecular disulfide-dependent redox signalling. Biochem. Soc. Trans. 42, 971-978.

Putker, M., Vos, H., van Dorenmalen, K., de Ruiter, H., Duran, A.G., Snel, B., Burgering, B.M., Vermeulen, M., and Dansen, T.B. (2014b). Evolutionary acquisition of cysteines determines FOXO paralog-specific redox signaling. Antioxid. Redox Signal. 22, 1528.

Radha, B.E., Hill, T.D., Rao, G.H.R., and White, J.G. (1985). GSH levels in human platelets display a circadian rythm in vitro. Trombos. Res. 40, 823-831.

Raghuram, S., Stayrook, K.R., Huang, P., Rogers, P.M., Nosie, A.K., McClure, D.B., Burris, L.L., Khorasanizadeh, S., Burris, T.P., and Rastinejad, F. (2007). Identification of heme as the ligand for the orphan nuclear receptors REV-ERBalpha and REV-ERBbeta. Nat. Struct. Mol. Biol. 14, 1207-1213.

Rainwater, R., Parks, D., Anderson, M.E., Tegtmeyer, P., and Mann, K. (1995). Role of cysteine residues in regulation of p53 function Mol. Cell. Biol. 15, 3892-3903.

Ramsey, K.M., Yoshino, J., Brace, S.C., Abrassart, D., Kobayashi, Y., Mercheva, B., Hong, H.-K., Chong, J.L., Buhr, E.D., Lee, C., et al. (2009). Circadian clock feedback cycle through NAMPTmediated NAD ${ }^{+}$biosynthesis. Science 324, 651-654.

Rehder, D.S., and Borges, C.R. (2010). Cysteine sulfenic acid as an intermediate in disulfide bond formation and nonenzymatic protein folding. Biochemistry 49, 7748-7755.

Reischl, S., Vanselow, K., Westermark, P.O., Thierfelder, N., Maier B., Herzel, H., and Kramer, A. (2007). Beta-TrCP1-mediated degradation of PERIOD2 is essential for circadian dynamics. J. Biol. Rhythms 22, 375-386.

Reppert, S.M., and Weaver, D.R. (2002). Coordination of circadian timing in mammals. Nature 418, 935-941.

Ripperger, J.A., and Schibler, U. (2006). Rhythmic CLOCK-BMAL1 binding to multiple E-box motifs drives circadian Dbp transcription and chromatin transitions. Nat. Genet. 38, 369-374.
Robles, M.S., Cox, J., and Mann, M. (2014). In-vivo quantitative proteomics reveals a key contribution of post-transcriptional mechanisms to the circadian regulation of liver metabolism. PLoS Genet. 10, e1004047.

Roenneberg, T., and Merrow, M. (2002). Life before the clock: modeling circadian evolution. J. Biol. Rhythms 17, 495-505.

Rosbash, M. (2009). The implications of multiple circadian clock origins. PLoS Biol. 7, 0421-0425.

Rutter, J., Reick, M., Wu, L.C., and McKnight, S.L. (2001). Regulation of clock and NPAS2 DNA binding by the redox state of NAD cofactors. Science 293, 510-514.

Sahar, S., Nin, V., Barbosa, M.T., Chini, E.N., and Sassone-Corsi, P. (2011). Altered behavioral and metabolic circadian rhythms in mice with disrupted NAD ${ }^{+}$oscillation. Aging 3, 794-802

Saini, C., Liani, A., Curie, T., Gos, P., Kreppel, F., Emmenegger, Y., Bonacina, L., Wolf, J.-P., Franken, P., and Schibler, U. (2013). Real-time recording of circadian liver gene expression in freely moving mice reveals the phase-setting behavior of hepatocyte clocks. Genes Dev. 27, 1526-1536.

Saini, C., Brown, S.A., and Dibner, C. (2015). Human peripheral clocks: applications for studying circadian phenotypes in physiology and pathophysiology. Front. Neurol. 6, 95.

Sato, T.K., Yamada, R.G., Ukai, H., Baggs, J.E., Miraglia, L.J., Kobayashi, T.J., Welsh, D.K., Kay, S.A, Ueda, H.R., and Hogenesch, J.B. (2006). Feedback repression is required for mammalian circadian clock function. Nat. Genet. 38, 312-319.

Schieber, M., and Chandel, N.S. (2014). ROS function in redox signaling and oxidative stress. Curr. Biol. 24, R453-R462.

Schmalen, I., Reischl, S., Wallach, T., Klemz, R., Grudziecki, A., Prabu, J.R., Benda, C., Kramer, A., and Wolf, E. (2014). Interaction of circadian clock proteins CRY1 and PER2 is modulated by zinc binding and disulfide bond formation. Cell 157, 1203-1215.

Shao, D., Oka, S., Liu, T., Zhai, P., Ago, T., Sciarretta, S., Li, H., and Sadoshima, J. (2014). A redox-dependent mechanism for regulation of AMPK activation by thioredoxin1 during energy starvation. Cell Metab. 19, 232-245.

Sobotta, M.C., Liou, W., Stöcker, S., Talwar, D., Oehler, M., Ruppert T., Scharf, A.N., and Dick, T.P. (2014). Peroxiredoxin-2 and STAT3 form a redox relay for $\mathrm{H}_{2} \mathrm{O}_{2}$ signaling. Nat. Chem. Biol. 11, 64-70.

Storz, G., Tartaglia, L. a, and Ames, B.N. (1990). Transcriptional regulator of oxidative stress-inducible genes: direct activation by oxidation. Science 248, 189-194.

Stringari, C., Wang, H., Geyfman, M., Crosignani, V., Kumar, V., Takahashi, J.S., Andersen, B., and Gratton, E. (2014). In vivo single-cell detection of metabolic oscillations in stem cells. Cell Rep. 10, 1-7

Sundaresan, M., Yu, Z.X., Ferrans, V.J., Irani, K., and Finkel, T. (1995). Requirement for generation of $\mathrm{H} 2 \mathrm{O} 2$ for platelet-derived growth factor signal transduction. Science 270, 296-299.

Sweeney, B., and Haxo, F. (1961). Persistence of a photosynthetic rhythm in enucleated acetabularia. Science 134, 1361-1363.

Tamaru, T., Hattori, M., Ninomiya, Y., Kawamura, G., Varès, G., Honda, K., Mishra, D.P., Wang, B., Benjamin, I., Sassone-Corsi, P., et al. (2013). ROS stress resets circadian clocks to coordinate pro-survival signals. PLoS One 8, e82006.

Tomita, J., Nakajima, M., Kondo, T., and Iwasaki, H. (2005). No transcription-translation feedback in circadian rhythm of KaiC phosphorylation. Science 307, 251-254.

Ueda, H.R. (2007). Systems biology of mammalian circadian clocks. Cold Spring Harb. Symp. Quant. Biol. 72, 365-380.

Vassilopoulos, A., Fritz, K.S., Petersen, D.R., and Gius, D. (2011). The human sirtuin family: evolutionary divergences and functions. Hum. Genomics 5, 485-496.

Vaziri, H., Dessain, S.K., Ng Eaton, E., Imai, S.I., Frye, R. a, Pandita, T.K., Guarente, L., and Weinberg, R.A. (2001). hSIR2(SIRT1) functions as an NAD-dependent p53 deacetylase. Cell 107, 149-159.

Wang, T.A., and Gillette, M.U. (2012). Circadian rhythm of redox state regulates excitability in suprachiasmatic nucleus neurons. Science 337, 839-842.

Webster, K.A., Prentice, H., and Bishopric, N.H. (2001). Oxidation of zinc finger transcription factors: physiological consequences. Antioxid. Redox Signal. 3, 535-548.

Welsh, D.K., Yoo, S.-H., Liu, A.C., Takahashi, J.S., and Kay, S.A. 
(2004). Bioluminescence imaging of individual fibroblasts reveals persistent, independently phased circadian rhythms of clock gene expression. Curr. Biol. 14, 2289-2295.

Welsh, D.K., Takahashi, J.S., and Kay, S.A. (2010). Suprachiasmatic nucleus: cell autonomy and network properties. Annu. Rev. Physiol. 72, 551-577.

Winterbourn, C.C., and Metodiewa, D. (1999). Reactivity of biologically important thiol compounds with superoxide and hydrogen peroxide. Free Radic. Biol. Med. 27, 322-328.

Winterbourn, C.C., and Hampton, M.B. (2008). Thiol chemistry and specificity in redox signaling. Free Radic. Biol. Med. 45, 549-561.

Woo, H.A., Chae, H.Z., Hwang, S.C., Yang, K.-S., Kang, S.W., Kim, K., and Rhee, S.G. (2003). Reversing the inactivation of peroxiredoxins caused by cysteine sulfinic acid formation. Science 300, 653-656.

Woo, H.A., Yim, S.H., Shin, D.H., Kang, D., Yu, D.-Y., and Rhee, S.G. (2010). Inactivation of peroxiredoxin I by phosphorylation allows localized $\mathrm{H}(2) \mathrm{O}(2)$ accumulation for cell signaling. Cell 140, 517-528.

Wood, Z.A, Poole, L.B., and Karplus, P.A. (2003). Peroxiredoxin evolution and the regulation of hydrogen peroxide signaling. Science 300, 650-653.

Wu, X., Bishopric, N.H., Discher, D.J., Murphy, B.J., Webster, K.A., Wu, X., Bishopric, N.H., Discher, D.J., Murphy, B.J., and Webster, K.A. (1996). Physical and functional sensitivity of zinc finger transcription factors to redox change. Mol. Cell. Biol. 16, 1035-1046.

Xu, Y.-Q., Zhang, D., Jin, T., Cai, D.-J., Wu, Q., Lu, Y., Liu, J., and Klaassen, C.D. (2012). Diurnal variation of hepatic antioxidant gene expression in mice. PLoS One 7, e44237.

Yang, G., Wright, C.J., Hinson, M.D., Fernando, A.P., Sengupta, S.,
Biswas, C., La, P., and Dennery, P.A. (2014). Oxidative stress and inflammation modulate Rev-erb $\alpha$ signaling in the neonatal lung and affect circadian rhythmicity. Antioxid. Redox Signal. 21, 17-32.

Yoo, S.-H., Yamazaki, S., Lowrey, P.L., Shimomura, K., Ko, C.H., Buhr, E.D., Siepka, S.M., Hong, H.-K., Oh, W.J., Yoo, O.J., et al (2004). PERIOD2::LUCIFERASE real-time reporting of circadian dynamics reveals persistent circadian oscillations in mouse peripheral tissues. Proc. Natl. Acad. Sci. USA 101, 5339-5346.

Yoshida, Y., ligusa, H., Wang, N., and Hasunuma, K. (2011). Crosstalk between the cellular redox state and the circadian system in Neurospora. PLoS One 6, e28227.

Yoshii, K., Tajima, F., Ishijima, S., and Sagami, I. (2015). Changes in $\mathrm{pH}$ and NADPH regulate the DNA binding activity of neuronal PAS domain protein 2, a mammalian circadian transcription factor. Biochemistry 54, 250-259.

Zhang, Q., Piston, D.W., and Goodman, R.H. (2002). Regulation of corepressor function by nuclear $\{$ NADH\}. Science $295,1895-$ 1897.

Zhang, E.E., Liu, Y., Dentin, R., Pongsawakul, P.Y., Liu, A.C., Hirota, T., Nusinow, D.A., Sun, X., Landais, S., Kodama, Y., et al. (2010) Cryptochrome mediates circadian regulation of cAMP signaling and hepatic gluconeogenesis. Nat. Med. 16, 1152-1156

Zhang, R., Lahens, N.F., Ballance, H.I., Hughes, M.E., and Hogenesch, J.B. (2014). A circadian gene expression atlas in mammals: Implications for biology and medicine. Proc. Natl. Acad. Sci. USA 111, 16219-16224.

Zhou, M., Wang, W., Karapetyan, S., Mwimba, M., Marqués, J., Buchler, N.E., and Dong, X. (2015). Redox rhythm reinforces the circadian clock to gate immune response. Nature 523, 472-476. 